\title{
A constitutive model for analyzing martensite formation in austenitic steels deforming at high strain rates
}

\author{
R. Zaera ${ }^{\mathrm{a}, *}$, J.A. Rodríguez-Martínez ${ }^{\mathrm{a}}$, A. Casado ${ }^{\mathrm{b}}$, J. Fernández-Sáez ${ }^{\mathrm{a}}$, A. Rusinek $^{\mathrm{c}}$, R. Pesci ${ }^{\mathrm{d}}$ \\ ${ }^{a}$ Department of Continuum Mechanics and Structural Analysis, University Carlos III of Madrid, Avda. de la Universidad, 30,28911 Leganés, Madrid, Spain \\ ${ }^{\mathrm{b}}$ Andritz Hydro, Paseo de la Castellana 163, 28046 Madrid, Spain \\ ${ }^{\mathrm{c}}$ Laboratory of Mechanics, Biomechanics, Polymers and Structures (LaBPS), National Engineering School of Metz (ENIM), Route d'Ars Laquenexy, CS65820, \\ 57078 Metz Cedex 3, France \\ d ENSAM-Arts et Métiers ParisTech, Laboratoire d'Etudes des Microstructures et de Mécanique des Matériaux LEM3, UMR CNRS 7239, 4 Rue Augustin Fresnel, \\ 57078 Metz Cedex 3, France
}

\section{Keywords:}

Martensitic transformation

TRIP steel

Strain rate

Viscoplasticity

Thermal softening

\begin{abstract}
A B S T R A C T
This study presents a constitutive model for steels exhibiting SIMT, based on previous sem inal works, and the corresponding methodology to estimate their parameters. The model includes temperature effects in the phase transformation kinetics, and in the softening of each solid phase through the use of a homogenization technique. The model was validated with experimental results of dynamic tensile tests on AISI 304 sheet steel specimens, and their predictions correlate well with the experimental evidence in terms of macroscopic stress strain curves and martensite volume fraction formed at high strain rates. The work shows the value of considering temperature effects in the modeling of metastable austen itic steels submitted to impact conditions. Regarding most of the works reported in the lit erature on SIMT, modeling of the martensitic transformation at high strain rates is the distinctive feature of the present paper.
\end{abstract}

\section{Introduction}

Worldwide demand for stainless steel has been increasing at a rate of about $6 \%$ per year for the last several decades, and is expected to increase at the same rate over the next decade. Among these, austenitic grades are the ones most commonly used in industry. The critical temperature at which the martensitic transformation occurs during cooling falls in these alloys due to their high content in nickel. This allows the material to remain completely austenitic after being quenched. The austenitic structure provides valuable properties for the steel, fostering its use in a number of industrial applications: sur gical instruments, houseware, containers, piping, vessels, power plants, pharmaceutical industry, petrochemical industry, food processing equipment, architecture and construction structures.

Some of the less highly alloyed austenitic (and yet largely used) grades are referred to as metastable because of their abil ity to transform from the initial face centered cubic austenite phase $\gamma$ to body centered cubic martensite $\alpha^{\prime}$. Austenite can be transformed to marteniste in different ways (Lichtenfeld et al., 2006; Curtze et al., 2009). Spontaneous transformation is dri ven by the difference in the chemical free energy of the two phases, when the material is cooled below the martensite start temperature $M_{s}$. Above $M_{s}$, Stress Assisted martensite forms in response to an applied elastic stress, which adds a mechanical driving force to the chemical free energy. This type of martensite transformation occurs until the steel reaches a temperature $M_{s}^{\sigma}$. Above this, the stress needed to start the transformation surpasses the flow stress of the $\gamma$ phase, which should harden by

\footnotetext{
* Corresponding author. Fax: +34 916249430.

E-mail address: ramon.zaera@uc3m.es (R. Zaera).
} 
plastic strain to extend the martensite formation process. This Strain Induced Martensitic Transformation (SIMT) acts as a new highly potent mechanism of $\alpha^{\prime}$ germination associated with plastic deformation. As temperature rises, austenite stability in creases to limit the transformation. The temperature above which martensite is not produced by plastic slip is referred to as $M_{d}$. The range $M_{s}^{\sigma}$ to $M_{d}$ corresponding to the SIMT process covers the in service temperatures reached by metastable austen itic steels during their plastic deformation in many industrial applications. Hence, besides the thermal softening shown by metal alloys (Farrokh and Khan, 2009; Khan and Meredith, 2010; Brunig and Gerke, 2011), the analysis of temperature ef fects in the deformation of austenitic steels presents particular interest.

The transformation of austenite into martensite is comparable to a dynamic composite effect due to the progressive appearance of the martensite during straining. The yield strength of martensite is usually higher than that of the austenite, increasing yield stress and strain hardening of the two phase steel (Petein, 2006). Additionally, the martensitic transforma tion causes the Transformation Induced Plasticity (TRIP) effect, and therefore steels showing SIMT are usually known as TRIP steels (Iwamoto et al., 1998). Two mechanisms are commonly proposed to explain transformation induced plasticity: Green wood and Johnson (1965) and Magee (1966). The first accounts for the instantaneous volume expansion and shape change produced by the martensitic transformation. This stress free strain of the formed martensite is accommodated in the sur rounding austenitic region, leading to redundant plastic deformation and, consequently, to extra strain hardening. The vol ume expansion of martensite is also beneficial to forming operations because it relaxes the tensile hydrostatic stress that can cause damage or micro cracking (Delannay et al., 2005). Magee's mechanism accounts for the preferred martensitic plates orientation caused by the loads applied, causing a non nil resultant of the shearing micro stresses and an average macro scopic shape change. These effects enhance the work hardenability of the steel, delay the onset of necking, and thus improve formability (Lichtenfeld et al., 2006; Dan et al., 2008; Oliver et al., 2007).

Different approaches have been proposed for constitutive models for SIMT. Olson and Cohen (1975) performed a one dimensional model for the kinetics of $\gamma \rightarrow \alpha^{\prime}$ transformation. They considered shear band intersections as sites for martens ite nucleation which lead to a characteristic sigmoidal equation for the volume fraction of martensite as a function of plastic strain. The model of Olson and Cohen (1975) was generalized by Stringfellow et al. (1992) for 3 D analysis, including the effect of stress triaxiality in the process and viscoplastic behavior of the phases. Papatriantafillou et al. $(2004,2006)$ coupled this model to a homogenization technique for nonlinear composites, proposed (Suquet, 1995a,b, 1996), and used it to deter mine forming limit diagrams for sheets made of multiphase TRIP steels. Other authors, such as Iwamoto et al. (1998), based their SIMT models on the work of Olson and Cohen (1975) including strain rate effects in the kinetics of shear band forma tion. Iwamoto and Tsuta (2002) used this model including the third invariant of the stress tensor in the yield function, as proposed by Miller and McDowell (1996), to show the dependence of the austenitic grain size on the deformation behavior of TRIP steels and to highlight the favorable effect of the strain induced martensitic transformation on the fracture toughness of TRIP steels. Han et al. (2004) proposed a model based on the approach of Olson and Cohen (1975), where the probability of martensite nucleation was derived for each variant as a function of the interaction energy between externally applied stress state and lattice deformation.

Other authors following different approaches have proposed models to describe SIMT. Cherkaoui et al. (1998) developed a constitutive equation for an austenitic single crystal undergoing transformation induced plasticity within a thermodynamic and micromechanical framework, following a classical scale transition method. This model has been used by Petit et al. (2007) to simulate the deformation behavior of the stainless steel as well as the corresponding transformation kinetics and texture evolution. Later, Cherkaoui et al. (2000) developed a micromechanical model to predict the conditions of nucle ation and growth of a martensitic microdomain within an inhomogeneous plastic strain field. Fisher et al. (2000) proposed a constitutive description of SIMT taking into account both the influence of transformation induced plastic strain and the influence of shear (orientation effect) on irreversible deformation. Garion and Skoczén (2002) proposed a simplified mar tensite evolution law to describe only the linear part of the sigmoidal curve, which has proven to be appropriate for cryo genic applications (Egner and Skoczén, 2010). Oberste Brandenburg and Bruhns (2004) described the behavior of TRIP steels based on a tensorial description of the thermodynamic driving force for the phase transformation. Dachkovski and Böhm (2004) presented a model of finite thermoplasticity with phase change based on the concept of isomorphism of elastic ranges, developed as an extension of the thermoplasticity theory of Bertram (1999). Garion et al. (2006) proposed a model to describe the FCC to BCC phase transformation in austenitic stainless steels based on the assumption of linearization of the most intensive part of the transformation curve. Hallberg et al. (2007) presented a model that takes basic thermodynamic relations as its starting point and treats the phase transition through an internal variable (the phase fractions) approach. Wolff et al. (2008) contributed to the numerical simulation of martensitic transformation laying a thermodynamic founda tion in the context of macroscopic continuum mechanics. The complex material behavior of the steel was modeled in the framework of small deformations, including phase transformation, plasticity and TRIP effect. Mahnken et al. (2009) pre sented a constitutive model formulated within a small strain theory, which combines the effects of viscoplasticity and TRIP. The main aim of the model was the simulation of metal forming and heat treatment of low alloy steels. Lee et al. (2010) pro posed a rate dependent crystal plasticity model which considers martensitic transformation, and used it to study the influ ence of strain rate (within the range $10{ }^{4} 10^{1} \mathrm{~s}^{1}$ ) on the deformation of a TRIP steel. Kubler et al. (2011) developed a semi phenomenological model for the thermomechanical behavior of TRIP aided steels. The model is based on a mean field description of the plastic and transformation strains in the different phases and presents the advantage, compared to a crys tallographic model, of a reduced number of internal variables, permitting its use in the simulation of metal forming processes. 
Most of the previous works focus on the analysis of the SIMT process under isothermal conditions. Only a small number consider non isothermal conditions to analyse forming, heat treatments or cryogenic applications of steel grades showing martensitic transformation. However, the temperature may rapidly and markedly increase in metastable austenitic steels under certain in service conditions. Due to their ductility and work hardening ability, these steels are used for energy absorption in crash (Andersson, 2005) or blast protection applications (Langdon and Schleyer, 2005a,b, 2006). These appli cations, involving high strain rates, are often accompanied by temperature rise due to the dissipation of plastic work. This means that the energy balance equation governing temperature evolution should involve terms arising from a thermome chanical coupling. The thermodynamic process deviates from the isothermal conditions and approaches adiabaticity, leading to large variations in the temperature field (Liang and Khan, 1999; Khan et al., 2004). Also, forming and machining processes, used to elaborate components made of metastable austenitic steels, take place under non isothermal conditions (Hänsel et al., 1998; Miguélez et al., 2009). Since temperature strongly affects the SIMT process, its effect on strain hardening and ductility of metastable austenitic steels deforming at high strain rates needs to be considered.

This work presents a constitutive model for steels exhibiting SIMT, based on the previous works of Olson and Cohen (1975), Stringfellow et al. (1992) and Papatriantafillou et al. (2004). The model proposes an original law to include the effect of temperature increase in the kinetics of phase transformation. Additionally, it considers temperature softening in the austenitic steel through the use of a homogenization technique to account for the thermoviscoplastic behavior of each solid phase. Based on previous experimental results of the authors, a procedure for determining the model constants has been developed and numerical simulations of tensile tests have been conducted in an explicit finite element code. The resulting predictions of the numerical model find good correlation with the experimental evidence in terms of macroscopic stress strain curves and martensite volume fraction formed during the course of plastic deformation. The analysis is focused on the AISI 304 grade, which may be considered as a reference metastable austenitic stainless steel for studying the SIMT pro cess at high strain rates, since it shows a large amount of transformed martensite even under adiabatic conditions. The work shows the value of considering the effect of temperature increase in the modeling of metastable austenitic steels submitted to impact loading.

\section{Fundamentals of the model developed}

\subsection{Model of Olson and Cohen (1975)}

Based on previous experimental works describing the sigmoidal shape of the transformation curves, and on the hypoth esis of intersection of shear bands in austenite as the dominant mechanism of SIMT, Olson and Cohen (1975) proposed a 1 D physical model which can predict the strain dependence of the kinetics of transformation. Under the assumption that the increase in the volume fraction of shear bands in the austenite $\dot{f}_{s b}$, in relation to shear band free volume ( $\left.1 f_{s b}\right)$, is propor tional to the plastic strain rate in the austenite $\dot{\bar{\varepsilon}}_{a}^{p}$

$$
\dot{f}_{s b} \quad\left(1 \quad f_{s b}\right) \alpha(\theta) \dot{\varepsilon}_{a}^{p},
$$

the creation of shear bands is fast at low plastic deformation and slower as the consumption of shear band free volume de creases. The $\alpha(\theta)$ parameter is expected to increase at low temperatures (Olson and Cohen, 1975; Iwamoto and Tsuta, 2002; Tomita and Iwamoto, 1995) favoring the shear band deformation mode. Such temperature dependence has frequently been defined as

$$
\alpha(\theta) \quad \alpha_{1} \theta^{2} \quad \alpha_{2} \theta+\alpha_{3},
$$

where $\theta$ is the absolute temperature and $\alpha_{1}, \alpha_{2}$ and $\alpha_{3}$ are positive material constants to be determined.

Considering a constant average volume $\bar{v}_{s b}$ of a shear band, and a power relation between the number of shear bands $N_{s b}$ and shear band intersections $N_{s b}^{I}$ (both per unit austenite volume), the latter can be written in terms of the volume fraction of shear bands

$$
N_{s b}^{I} \quad K\left(\frac{f_{s b}}{v_{s b}}\right)^{n}
$$

$K$ and $n$ being constants of the potential law. Now, with the assumption of a probability $P$ that a shear band intersection acts as a martensite nucleation site, and a constant average volume of martensitic units $\bar{v}_{m}$, the rate of increase in the martensite volume fraction $f_{m}$ is thus given as

$$
\frac{\dot{f}_{m}}{1 \quad f_{m}} \quad v_{m} P \dot{N}_{s b}^{I} \text {. }
$$

Eqs. (1) (4) may be integrated under isothermal conditions (no change in $\alpha$ and of probability of martensitic nucleation $P$ ) and the kinetics of SIMT is described by a simple relation

$$
f_{m} \quad 1 \quad \exp \left[\begin{array}{ll}
\beta(1 & \left.\exp \left(\alpha \varepsilon_{a}^{p}\right)\right)^{n}
\end{array}\right],
$$


$\beta$ being

$\beta \quad \beta_{0} P$,

with

$$
\beta_{0} \frac{v_{m} K}{\left(v_{s b}\right)^{n}}
$$

\subsection{Model of Stringfellow et al. (1992)}

Stringfellow et al. (1992) recasted the model of Olson and Cohen (1975) in a generalized 3 D and rate form, and also in cluded the effect of triaxiality in the SIMT, considering the acceleration of martensitic transformation in uniaxial tension compared to uniaxial compression observed previously by other authors (Young, 1988). Starting from Eq. (4), the kinetics of martensitic transformation is given by

$$
\frac{\dot{f}_{m}}{1 \quad f_{m}} \quad v_{m} \dot{N}_{m}
$$

where the rate of martensite embryos per unit volume $\dot{N}_{m}$ is now given by the rate of the product $N_{s b}^{l} P$

$$
\dot{N}_{m} \quad P \dot{N}_{s b}^{I}+N_{s b}^{I} \dot{P} U(\dot{P}) .
$$

$N_{s b}^{I}$ being the number of shear band intersections per unit volume and $P$ the probability that a shear band intersection acts as a nucleation site. $U(\circ)$ is the Heaviside unit step function, included to capture the irreversibility of transformation. Stringfel low et al. (1992) proposed a Gaussian cumulative probability distribution function to calculate $P$

$$
P(g) \quad \frac{1}{\sqrt{ } 2 \pi s_{g}} \int_{\infty}^{g} \exp \left[\frac{1}{2}\left(\frac{\tilde{g}}{s_{g}}\right)^{2}\right] d \tilde{g},
$$

$\bar{g}$ and $s_{g}$ being, respectively, the mean and standard deviation of the normal distribution function. Moreover, $g$ is a normal ized thermodynamic driving force for the martensitic transformation, dependent on temperature and triaxiality

$$
\begin{array}{lll}
g & g_{0} & g_{1} \Theta+g_{2} \Sigma \\
\hline
\end{array}
$$

where $g_{0}, g_{1}$ and $g_{2}$ are dimensionless constants. $\Theta$ is a normalized temperature related to the absolute temperature $\theta$ by the following expression

$$
\Theta \frac{\theta \quad M_{s}^{\sigma}}{M_{d} \quad M_{s}^{\sigma}} .
$$

$M_{d}$ being the upper temperature limit for phase transformation and $M_{s}^{\sigma}$ the lower limit temperature for strain induced mar tensitic nucleation. $\Sigma$ is the triaxiality defined as the ratio between hydrostatic stress $\sigma_{H}=(\boldsymbol{\sigma}: \mathbf{1}) / 3$ and Mises equivalent stress $\bar{\sigma} \quad \sqrt{ } 3 / 2 \mathbf{s}: \mathbf{s}$ (s stress deviator tensor).

The rate of $P$, under isothermal conditions, is thus given by

$$
\dot{P} \frac{g_{2}}{\sqrt{ } 2 \pi s_{g}} \exp \left[\frac{1}{2}\left(\frac{g g}{s_{g}}\right)^{2}\right] \dot{\Sigma} .
$$

Stringfellow et al. (1992) derived from Eqs. (1), (3), (8) and (9) an evolution equation for the volume fraction of martensite

$$
\dot{f}_{m} \quad\left(1 \quad f_{m}\right)\left(A_{f} \dot{\varepsilon}_{a}^{p}+B_{f} \dot{\Sigma}\right)
$$

where the factor associated with plastic deformation in austenite is given by

$$
A_{f} \quad \beta_{0} \alpha n\left(1 \quad f_{s b}\right)\left(f_{s b}\right)^{n}{ }^{1} P
$$

and the factor associated to the probability of martensite nucleation by

$$
B_{f} \quad \beta_{0}\left(f_{s b}\right)^{n} \frac{g_{2}}{\sqrt{ } 2 \pi s_{g}} \exp \left[\frac{1}{2}\left(\frac{g}{s_{g}}\right)^{2}\right] U(\dot{P}) .
$$

Stringfellow et al. (1992) complemented the above scalar equations defining the kinetics of the SIMT with the generalized Hooke's law for hypoelastic plastic materials

$$
\boldsymbol{\sigma}^{\nabla} \quad \mathbf{C}: \mathbf{d}^{e} \quad \mathbf{C}:\left(\mathbf{d} \quad \mathbf{d}^{p}\right),
$$


where $\boldsymbol{\sigma}^{\nabla}$ is an objective derivative of the Cauchy stress tensor, $\mathbf{d}, \mathbf{d}^{e}$ and $\mathbf{d}^{p}$ are respectively the total, elastic, and inelastic rate of deformation tensors, and $\mathbf{C}$ is the Hooke tensor for isotropic elasticity, defined by the elastic constants $K$ and $G$. The same authors introduced the following decomposition of the inelastic rate of deformation tensor

$$
\mathbf{d}^{p} \quad \mathbf{d}^{\text {slip }}+\mathbf{d}^{\text {nucl }},
$$

where $\mathbf{d}^{\text {slip }}$ represents the rate of deformation due to slip in the multiphase material, and $\mathbf{d}^{\text {nucl }}$ represents an additional inelastic rate of deformation caused by the transformation process. The latter deformation rate was incorporated to consider strain softening that occurs as a result of the transformation process, and it is broken down into a deviatoric term (modeling the transformation shape) and a dilatational term (accounting for the transformation volume change):

$$
\mathbf{d}^{\text {nucl }} \quad \dot{f}_{m}\left(A_{\sigma} \mathbf{N}+\frac{1}{3} \Delta_{V} \mathbf{1}\right) \text {. }
$$

$\mathbf{N}$ being the direction of the deviatoric stress

$$
\text { N } \frac{3}{2} \frac{\mathbf{s}}{\sigma} \text {. }
$$

According to Olson and Azrin (1978), the parameter $A_{\sigma}$ is taken to depend on the stress level $\bar{\sigma}$

$$
A_{\sigma} \quad A_{0}+A_{1} \frac{\sigma}{S_{a}^{*}} .
$$

$A_{0}$ and $A_{1}$ being dimensionless constants and $s_{a}^{*}$ a reference austenitic stress. Regarding the dilatational term in Eq. (19), $\Delta_{V}$ is the relative volume change associated with transformation

$$
\Delta_{V} \quad \frac{V_{m} \quad V_{a}}{V_{a}},
$$

where $V_{m}$ and $V_{a}$ represent the unstressed relative volumes of martensite and austenite. Leal (1984) found experimentally that $0.02 \leqslant \Delta_{V} \leqslant 0.05$ in austenitic steels. The deviatoric part of $\mathbf{d}^{p}$, including both slip and transformation parts, is chosen to be coaxial with the deviatoric stress $\mathbf{s}$, and both are related through a self consistent homogenization method for predict ing the equivalent stress strain behavior of the polycrystalline composite material. Stringfellow et al. (1992) considered that each phase behaves as a viscoplastic material with power laws for strain as well as strain rate hardenings. To complete their model, they assumed that each incremental unit of martensite has an initial yield stress which is a function of the plastic strain in austenite from which it was instantaneously produced. A mixture law is used to determine the average martensite yield stress so that martensite, which forms at a given austenite plastic strain, inherits the strain hardened dislocation struc ture of its parent austenite.

\subsection{Model of Papatriantafillou et al. $(2004,2006)$}

Papatriantafillou et al. $(2004,2006)$ recasted the model of Stringfellow et al. (1992), preserving its main characteristics and including the following features. The inelastic strain due to slip is determined with a homogenization method previously proposed by Suquet (1995a,b, 1996) to determine the effective properties in nonlinear composites: in this case, a four phase steel (ferrite, bainite, austenite and martensite) in which isotropic viscoplastic phases are distributed uniformly and isotrop ically. According to this theory, the inelastic strain due to slip $\mathbf{d}^{\text {slip }}$ is related to the direction of the deviatoric stress through the expression

$$
\mathbf{d}^{\text {slip }} \dot{\varepsilon}^{\text {sip }} \mathbf{N}
$$

with

$$
\dot{\varepsilon}^{s l i p} \frac{\xi^{h o m}}{3} \sigma,
$$

$\xi^{\text {hom }}$ being the inverse of the overall viscous shear modulus of the homogenized medium, which may be obtained by using the modified secant procedure described by Suquet (1995a,b, 1996). This procedure requires the knowledge of the plastic flow rule of each phase $i$, for which Papatriantafillou et al. $(2004,2006)$ proposed the following viscous potential

$$
\Psi_{i} \quad \frac{\sigma_{Y i} \dot{\varepsilon}_{0 i}}{\frac{1}{m_{i}}+1}\left(\frac{\sigma_{i}}{\sigma_{Y i}}\right)^{\frac{1}{m_{i}}+1} .
$$

The flow rule determines the plastic strain rate tensor for each phase

$$
\mathbf{d}_{i}^{p} \quad \frac{\partial \Psi_{i}}{\partial \boldsymbol{\sigma}_{i}} \quad \dot{\varepsilon}_{0 i}\left(\frac{\sigma_{i}}{\sigma_{Y i}}\right)^{\frac{1}{m_{i}}} \mathbf{N}_{i}
$$


and the equivalent plastic strain rate is then given by

$$
\dot{\varepsilon}_{i}^{p} \quad \dot{\varepsilon}_{0 i}\left(\frac{\sigma_{i}}{\sigma_{Y i}}\right)^{\frac{1}{m_{i}}} .
$$

In the above equations, $\dot{\bar{\varepsilon}}_{0 i}$ is a reference strain rate, $m_{i}$ is the strain rate sensitivity, and $\sigma_{Y i}$ is a reference yield stress accounting for plastic strain hardening in the form of a Ludwik law

$$
\sigma_{Y i} \quad \sigma_{0 i}+H_{i}\left(\varepsilon_{i}^{p}\right)^{n_{i}} .
$$

Calculation of $\xi^{\text {hom }}$ requires the solution of a nonlinear system of algebraic equations, in which the equivalent stresses at the different phases $\bar{\sigma}_{i}$ are determined as well.

\section{Proposed modifications for the model}

Since the model is to be used for an austenitic steel, it takes into account a two phase $\gamma \quad \alpha^{\prime}$ structure. The adiabatic in crease in temperature during deformation at high strain rates is considered, hence several modifications to the previous models are proposed, affecting the following aspects:

- Kinetics of SIMT. The parameter $\alpha$ decreases with temperature, as observed by Olson and Cohen (1975). The following phe nomenological law is proposed to fit this dependence

$$
\alpha(\Theta) \quad \alpha_{0}\left[\begin{array}{lll}
1 & \Theta \exp \left(\alpha_{1}\left(1 \quad \Theta{ }^{1}\right)\right)
\end{array}\right]
$$

$\Theta$ being the normalized temperature related to the absolute temperature $\theta$ by Eq. (12). In comparison with the polynomial expressions applied by other authors to describe the change of $\alpha$ with temperature (Olson and Cohen, 1975; Iwamoto and Tsuta, 2002; Tomita and Iwamoto, 1995), the one proposed in this work facilitates to capture the decrease of the transfor mation rate with increasing temperature within the temperature range in which the SIMT occurs. In this work, the linearly temperature dependent formulation proposed by Stringfellow et al. (1992) for the thermodynamic driving force (used to de scribe martensite formation under static loading) is replaced by an exponential equation.

$$
g \quad g_{0} \exp \left(g_{1} \Theta\right)+g_{2} \Sigma .
$$

The new law provides greater temperature sensitivity of the rate of martensitic transformation. This becomes relevant at high strain rates where the temperature rise of the material results from the adiabatic character of the plastic deformation. According to the experimental results reported by Rodríguez Martínez et al. (2011) at high deformation rates (and therefore under significant temperature increase), small variations on the rise of temperature lead to relevant differences on the vol ume fraction of martensite formed.

The rate of change of $P$, and the equation for the evolution of the volume fraction of martensite, are now given by

$$
\begin{array}{ll}
\dot{P} & \frac{1}{\sqrt{ } 2 \pi s_{g}} \exp \left[\frac{1}{2}\left(\frac{g}{s_{g}}\right)^{2}\right] \dot{g}, \\
\dot{f}_{m} & f_{a}\left(A_{f} \dot{\varepsilon}_{a}^{p}+B_{f} \dot{g}\right) .
\end{array}
$$

Now the temperature rate needs to be considered in the expression of the rate of $g$

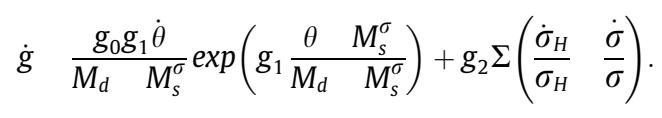

Thus, according to Eq. (31), the factor $B_{f}$ in Eq. (32) may be written as

$$
B_{f} \quad \beta_{0}\left(f_{s b}\right)^{n} \frac{1}{\sqrt{ } 2 \pi s_{g}} \exp \left[\frac{1}{2}\left(\frac{g r}{s_{g}}\right)^{2}\right] U(\dot{g}) .
$$

The rate of austenite volume fraction is easily determined, taking into account the two phase structure of the austenitic steel

$$
\dot{f}_{a} \quad \dot{f}_{m}
$$

- Decomposition of the rate of deformation tensor. The rate of thermal deformation tensor is included and assumed to be isotropic

$$
\mathbf{d}^{\theta} \quad \alpha_{\theta} \dot{\theta} \mathbf{1}
$$

$\alpha_{\theta}$ being the coefficient of thermal expansion. Mahnken et al. (2009) used a rule of mixtures to calculate $\alpha_{\theta}$ taking into ac count the different coefficients for thermal expansion of martensite and austenite. However, different authors (Sideridis et al., 2005) shown that the thermal expansion coefficient does not obey the law of mixtures because a state of microstresses 
appears between the phases when submitted to a temperature increase. Therefore the authors have chosen a constant and characteristic value of $\alpha_{\theta}$. Hooke's law now includes thermal strain

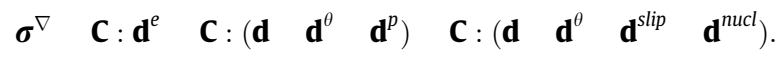

- Yield stresses. Now the temperature is included to consider thermal softening on each solid phase. Thus, each phase is assumed to behave according to the following potential

$$
\Psi_{i} \quad \frac{\sigma_{Y i}\left(\varepsilon_{i}^{p}\right) h\left(\theta_{i}\right) \dot{\varepsilon}_{0 i}}{\frac{1}{m_{i}}+1}\left(\frac{\sigma_{i}}{\sigma_{Y i}\left(\varepsilon_{i}^{p}\right) h\left(\theta_{i}\right)}\right)^{\frac{1}{m_{i}}+1}
$$

and

$$
\mathbf{d}_{i}^{p} \quad \frac{\partial \Psi_{i}}{\partial \boldsymbol{\sigma}_{i}} \quad \frac{1}{2 \mu_{i}} \mathbf{s}_{i},
$$

$\mu_{i}$ being the shear modulus of phase $i$ given by

$$
\frac{1}{\mu_{i}} \quad \xi_{i} \frac{3 \dot{\varepsilon}_{0 i}}{\sigma_{Y i}\left(\varepsilon_{i}^{p}\right) h\left(\theta_{i}\right)}\left(\frac{\sigma_{i}}{\sigma_{Y i}\left(\varepsilon_{i}^{p}\right) h\left(\theta_{i}\right)}\right)^{\frac{1}{m_{i}} 1}
$$

and $\xi_{i}$ being the shear compliance. Then, the equivalent plastic strain rate is given by

$$
\dot{\varepsilon}_{i}^{p} \quad\left(\frac{2}{3} \mathbf{d}_{i}^{p}: \mathbf{d}_{i}^{p}\right)^{1 / 2} \quad \dot{\varepsilon}_{0 i}\left(\frac{\sigma_{i}}{\sigma_{Y i}\left(\varepsilon_{i}^{p}\right) h\left(\theta_{i}\right)}\right)^{\frac{1}{m_{i}}} .
$$

The selection of a potential is not unique. If the following temperature dependent function is chosen

$$
h\left(\theta_{i}\right) \quad\left(\frac{\theta_{i}}{\theta_{0 i}}\right)^{v_{i}},
$$

$v_{i}$ being the thermal sensitivity of phase $i$ and $\theta_{0 i}$ a reference temperature, the proposed potential has the advantage of lead ing to a power law for both viscous and thermal effects. These laws are commonly accepted to model strain rate hardening and temperature softening (Klepaczko, 1987; Molinari et al., 2002; Mercier and Molinari, 2004; Khan et al., 2007). Using a Ludwik law

$$
\sigma_{Y i}\left(\varepsilon_{i}^{p}\right) \quad \sigma_{0 i}+H_{i}\left(\varepsilon_{i}^{p}\right)^{n_{i}} .
$$

Eq. (41) leads to the following thermoviscoplastic law for each phase

$$
\sigma_{i} \quad\left(\sigma_{0 i}+H_{i}\left(\varepsilon_{i}^{p}\right)^{n_{i}}\right)\left(\frac{\dot{\varepsilon}_{i}^{p}}{\dot{\varepsilon}_{0 i}}\right)^{m_{i}}\left(\frac{\theta_{i}}{\theta_{0 i}}\right)^{v_{i}} .
$$

Different techniques have been proposed to determine the effective properties of viscoplastic heterogeneous materials (Love and Batra, 2006; Mercier and Molinari, 2009). In this work they are calculated with the modified secant method proposed by Suquet (1995a,b, 1996), which has been extended for thermal softening effects. Applied to a statistically isotropic and incom pressible composite, this method permits to obtain homogeneous properties through the solution of $2 \mathrm{~N}$ non linear equa tions, $N$ being the number of phases. In our case the 4 equations are $(i=1,2)$

$$
\begin{aligned}
& \xi_{i} \frac{3 \dot{\varepsilon}_{0 i}}{\sigma_{Y i}\left(\varepsilon_{i}^{p}\right) h\left(\theta_{i}\right)}\left(\frac{\sigma_{i}}{\sigma_{Y i}\left(\varepsilon_{i}^{p}\right) h\left(\theta_{i}\right)}\right)^{\frac{1}{m_{i}} 1}, \\
& \sigma_{i} \quad \sigma\left(\frac{1}{f_{i}} \frac{\partial \xi_{h o m}}{\partial \xi_{i}}\right)^{1 / 2}
\end{aligned}
$$

with unknowns $\xi_{i}$ and $\bar{\sigma}_{i}$. The homogenization method requires a linear theory providing an expression of the effective com pliance $\xi_{\text {hom }}$ relating stress and strain rate

$$
\mathbf{d}^{\text {slip }} \frac{\xi_{\text {hom }}}{2} \mathbf{s} .
$$

As proposed by Papatriantafillou et al. (2006), a Hashin Shtrikman lower bound was chosen to estimate the shear modulus of the homogeneous material, considered as a composite with incompressible phases, distributed statistically uniformly and isotropically. Hashin Shtrikman bounds for the homogeneous shear modulus $\mu_{\text {hom }}=1 / \xi_{\text {hom }}$ are given by (see Willis, 1982)

$$
\mu_{\text {hom }} \frac{\sum_{i} f_{i} \frac{5 \mu(3 \kappa+4 \mu) \mu_{i}}{6 \mu_{i}(\kappa+2 \mu)+\mu(9 \kappa+8 \mu)}}{\sum_{i} f_{i} \frac{5 \mu(3 \kappa+4 \mu)}{6 \mu_{i}(\kappa+2 \mu)+\mu(9 \kappa+8 \mu)}},
$$


$\mu_{i}$ is the shear modulus of phase $i$, and $\mu$ and $\kappa$ the shear and volumetric modulii of the homogeneous comparison material. If each phase is incompressible $\left(\kappa_{i} \rightarrow \infty\right)$, the homogeneous shear modulus is given by

$$
\mu_{\text {hom }} \frac{\sum_{i} \frac{f_{i} \mu_{i}}{2 \mu_{i}+3 \mu}}{\sum_{i} \frac{f_{i}}{2 \mu_{i}+3 \mu}} .
$$

This expression yields to the greatest lower bound by setting $\mu=\min \left(\mu_{i}\right)$ for each phase $i$ (Willis, 1982). Then, for an austen ite/martensite composite with austenite as soft phase

$$
\mu_{\text {hom }} \frac{\mu_{a}\left(3 f_{a} \mu_{a}+2 f_{a} \mu_{m}+5 f_{m} \mu_{m}\right)}{3 f_{a} \mu_{a}+5 f_{m} \mu_{a}+2 f_{a} \mu_{m}} .
$$

The set of non linear equations were solved using the method proposed by Papatriantafillou et al. (2006). Once they are solved, the effective compliance $\xi_{\text {hom }}$ is calculated as $\mu_{\text {hom }}^{1}$ using Eq. (50).

- Temperature increase. Under adiabatic conditions and with plastic work as only heat source, the heating power equals plastic power, and the temperature rate can be calculated with the following expression

$$
\rho c_{v} \dot{\theta} \quad \eta^{q t} \sigma \dot{\varepsilon}^{s l i p},
$$

$\eta^{q t}$ being the Quinney Taylor coefficient (considered constant), $c_{v}$ the specific heat and $\rho$ the density which, according to the principle of mass conservation, is updated as

$$
\rho \frac{\rho_{0}}{\operatorname{det}(\mathbf{F})} .
$$

$\mathbf{F}$ being the deformation gradient tensor. Alternatively, the temperature increment may be calculated by averaging the two phases of the steel

$$
\dot{\theta} \quad \sum_{i=1}^{2} f_{i} \frac{\eta_{i}^{q t}}{\rho_{i} c_{v i}} \sigma_{i} \dot{\varepsilon}_{i}^{p} .
$$

A similar additive expression was used by Kuchniki et al. (2008) to define the temperature change taking into account slip strain rates on different slip systems. No difference was found in the numerical results using Eq. (51) or Eq. (53) taking the same densities, specific heat coefficients and Quinney Taylor coefficients for all phases; thus, the first one was adopted for simplicity.

The contribution of latent heat due to phase transformation has been identified by Rusinek and Klepaczko (2009) as a non negligible heat source during plastic deformation of steels exhibiting $\gamma \rightarrow \alpha^{\prime}$ transformation. However the experimental data does not allow a precise determination of the latent heat that would be required to consider it in the model through an additional term in the equation of the first principle of thermodynamics (Eq. (51)). Since the most widely used value of the Quinney Taylor coefficient for steels is $\eta^{q t}=0.9$ and the upper value of latent heat in dynamic tensile test at $\dot{\varepsilon} \geqslant 10 \mathrm{~s}{ }^{1}$ is $10 \%$ compared to the average temperature rise due to plastic work (according to the estimation by Rusinek and Klepaczko, 2009), a value of $\eta^{q t}=1$ has been chosen to consider both sources of heat: the conversion of plastic work and the martensitic transformation.

\section{Integration procedure}

\subsection{Constitutive model in a corotational frame}

For the integration of the above set of nonlinear rate equations in a finite deformation frame, incremental objectivity is achieved by rewriting them in a corotational configuration (Simo and Hughes, 1998; Doghri, 2000; Hagege, 2004). To formal ize this approach, $\boldsymbol{\varpi}$ being a spatial skew symmetric tensor, a group of rotations $\Re$ can be generated so that

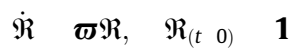

with

$$
\boldsymbol{\varpi} \boldsymbol{\varpi}^{T}
$$

and

$$
\Re^{1} \mathfrak{R}^{T},
$$

$t$ being time. Typical choices of $\boldsymbol{\varpi}$ include the spin tensor $\boldsymbol{w}$ and the tensor $\boldsymbol{\Omega}$ defined as

$$
\Omega \quad \dot{R} \boldsymbol{R}^{T},
$$

where $\boldsymbol{R}$ is the polar rotation tensor. The Cauchy stress tensor and the rate of deformation tensor are rotated as 


$$
\boldsymbol{\sigma}_{\Re} \quad \mathfrak{R}^{T} \boldsymbol{\sigma} \mathfrak{R}, \quad \mathbf{d}_{\mathfrak{R}} \quad \mathfrak{R}^{T} \mathbf{d} \mathfrak{R} .
$$

Time differentiation of the rotated Cauchy stress leads to

$$
\dot{\boldsymbol{\sigma}}_{\mathfrak{R}} \quad \mathfrak{R}^{T}(\dot{\boldsymbol{\sigma}}+\boldsymbol{\sigma} \boldsymbol{\sigma} \quad \boldsymbol{\boldsymbol { \sigma } \sigma}) \mathfrak{R} \quad \mathfrak{R}^{T} \boldsymbol{\sigma}^{\nabla} \mathfrak{R} .
$$

Here, $\boldsymbol{\sigma}^{\nabla}$ coincides with the Jaumann stress rate if $\boldsymbol{\sigma}=\boldsymbol{w}$. The Hughes Winget algorithm (Hughes and Winget, 1980) is used to compute $\mathfrak{R}$ in this case with an approximated formula valid for small increments. If $\boldsymbol{\varpi}$ is chosen to be equal to $\omega$ (and hence $\mathfrak{R} \boldsymbol{R}), \boldsymbol{\sigma}^{\nabla}$ coincides with the Green Naghdi McInnis stress rate (Khan and Huang, 1995). Thus, a complicated objec tive stress rate can be computed as a simple time derivative. Taking advantage of the orthogonality of $\mathfrak{R}$, the symmetry of the Cauchy stress and rate of deformation tensors and the isotropy of the elastic tensor $\left(\mathbf{C}_{\mathfrak{R}} \quad \mathbf{C}\right)$, the constitutive equations de fined above, in which tensors are involved, are form identical in the corotational configuration but with spatial variables now replaced by rotated variables. Moreover, all the constitutive equations of the model involving only scalars remain unchanged.

The increment of total deformation in the corotational frame $\Delta \boldsymbol{\varepsilon}_{\Re}$, needed for the corotational formulation of Eq. (61) could be determined by an objective approximation of the rate of deformation tensor $\mathbf{d}_{n+1 / 2}$ calculated by the midpoint rule (Simo and Hughes, 1998; Doghri, 2000).

\subsection{Discretization of the constitutive equations}

Within the finite element method, the integration process is local in space, it occurs at quadrature points of the finite ele ments. The incremental integration of the constitutive model is regarded as a strain driven process, in which the total strain tensor increment at each quadrature point is given at a certain time and both the stress and the state variables should be updated. Within the frame of the corotational configuration, the return mapping algorithm is proposed to solve the above equations. An implicit scheme is used to discretize all the equations. Although all the variables $\left(\boldsymbol{\sigma}, \mathbf{s}, \mathbf{N}, \bar{\sigma}, \sigma_{H}, A_{f}, B_{f}, \xi^{\text {hom }}, A_{\sigma}, \dot{\bar{\varepsilon}}_{a}^{p}, f_{a}, \rho, \theta\right)$ are evaluated at time $n+1$, the subindex is omitted for simplicity. The cor responding updated stress is then written as

$$
\boldsymbol{\sigma} \boldsymbol{\sigma}^{\text {trial }}+\Delta \boldsymbol{\sigma}^{\theta}+\Delta \boldsymbol{\sigma}^{\text {ret }}
$$

where trial stress is given by

$$
\boldsymbol{\sigma}^{\text {trial }} \boldsymbol{\sigma}_{n}+\mathbf{C}: \Delta \boldsymbol{\varepsilon}
$$

with $\sigma_{n}$ being the stress at time $n$ and $\Delta \boldsymbol{\varepsilon}$ the increment of total deformation. The increment due to thermal stress is calcu lated with

$$
\Delta \boldsymbol{\sigma}^{\theta} \quad 3 K \alpha_{\theta} \Delta \theta \mathbf{1}
$$

and $\Delta \boldsymbol{\sigma}^{\text {ret }}$ is given by

$$
\Delta \boldsymbol{\sigma}^{r e t} \quad \mathbf{C}: \Delta \boldsymbol{\varepsilon}^{p} \quad \mathbf{C}:\left(\Delta \boldsymbol{\varepsilon}^{\text {slip }}+\Delta \boldsymbol{\varepsilon}^{\text {nucl }}\right) \quad \mathbf{C}:\left(\Delta \varepsilon_{q} \mathbf{N}+\Delta \varepsilon_{V} \mathbf{1}\right)
$$

with

$$
\begin{array}{ll}
\Delta \varepsilon_{q} & \frac{1}{3} \sigma \xi^{h o m} \Delta t+A_{\sigma} \Delta f_{m}, \\
\Delta \varepsilon_{V} & \frac{1}{3} \Delta f_{m} \Delta_{V} .
\end{array}
$$

The increments in martensite volumetric fraction $f_{m}$ and thermodynamic driving force $g$ are given by

$$
\begin{aligned}
& \Delta f_{m} \quad f_{a}\left(A_{f} \dot{\varepsilon}_{a}^{p} \Delta t+B_{f} \Delta g\right),
\end{aligned}
$$

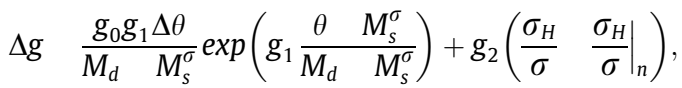

$\xi^{\text {hom }}$ in Eq. (64) and $\dot{\bar{\varepsilon}}_{a}^{p}$ in Eq. (66) are determined with the homogenization process. Symbol $\left.\right|_{n}$ in Eq. (67) indicates that cor responding variables should be evaluated at the beginning of the time step. The functional dependency of $\Delta f_{m}$ shows that the model takes into account the historical effects of strain rate, temperature, and loading path on the martensitic transforma tion. Eq. (60) then leads to the following expression for updated stress

$$
\begin{array}{lllll}
\boldsymbol{\sigma} & \boldsymbol{\sigma}^{\text {trial }} & 3 K \alpha_{\theta} \Delta \theta \mathbf{1} & 2 G \Delta \varepsilon_{q} \mathbf{N} & 3 K \Delta \varepsilon_{V} \mathbf{1}
\end{array}
$$

with deviatoric and hydrostatic parts

$$
\begin{aligned}
& \text { s } \mathbf{s}^{\text {trial }} 2 G \Delta \varepsilon_{q} \mathbf{N} \text {, } \\
& \sigma_{H} \quad \sigma_{H}^{\text {trial }} \quad 3 K \alpha_{\theta} \Delta \theta \quad 3 K \Delta \varepsilon_{V} .
\end{aligned}
$$


From Eq. (68), it is easily shown that $\mathbf{s}$ and $\mathbf{s}^{\text {trial }}$ are collinear, and then $\mathbf{N}$ is known once the trial stress has been calculated

$$
\mathbf{N} \frac{3}{2} \frac{\mathbf{s}}{\sigma} \quad \frac{3}{2} \frac{\mathbf{s}^{\text {trial }}}{\sigma^{\text {trial }}}
$$

leading to the following scalar equation

$$
\sigma \quad \sigma^{\text {trial }} 3 G \Delta \varepsilon_{q} .
$$

The volume fraction of austenite may be calculated with the following expression

$$
f_{a} \quad 1 \quad\left(\left.f_{m}\right|_{n}+\Delta f_{m}\right) .
$$

Symbol $\left.\right|_{n}$ in Eq. (73) indicates that $f_{m}$ should be evaluated at the beginning of the time step. Finally, the temperature increment $\Delta \theta$ is determined with

$$
\Delta \theta \quad \frac{\eta^{q t}}{\rho c_{v}} \sigma \dot{\varepsilon}^{s l i p} \Delta t
$$

The set of non linear incremental equations is solved with an iterative algorithm, which has been implemented in $A B A$ QUS/Explicit (HKS, 2003) through a user subroutine VUMAT. This code performs the integration of the constitutive model in a corotational frame defined by the polar rotation tensor $\boldsymbol{R}$, corresponding to the Green Naghdi McInnis objective stress rate. The numerical tool serves to analyze the influence of adiabatic temperature increase during the deformation of austen itic steels exhibiting SIMT.

\section{Strain induced martensitic transformation in AISI 304 steel at high strain rates}

If the number of related publications is taken into account (Iwamoto et al., 1998; Angel, 1954; De et al., 2006; Hecker et al., 1982; Mertinger et al., 2008; Tomita and Iwamoto, 1995; Tomita and Iwamoto, 2001), the AISI 304 can be considered to be the reference metastable austenitic stainless steel for studying the SIMT process. The AISI 304 belongs to the type called high alloy TRIP steels. These types of steel contain a large amount of alloying elements such as $\mathrm{Cr}$ and $\mathrm{Ni}$, improving pitting and corrosion resistance. The chemical composition of the material is given in Table 1.

This steel grade is considered the most versatile and most widely used stainless steel. It serves a wide range of applica tions because of its strength, work hardening and ductility, as well as its excellent formability. Such improved mechanical properties are a direct result of the martensitic transformation occurring in this material during the course of plastic defor mation. Therefore, determination of the loading conditions under which martensite is formed in the AISI 304 is desirable. This is useful for evaluating the benefits that this material could provide in engineering applications.

Recent works conducted by the authors (Rusinek et al., 2010; Rodríguez Martínez et al., 2010b, 2011) follow that direc tion, examining the ability of this steel grade for energy absorption under impact loading. It has been observed that the per formance of the AISI 304 under impact was excellent in comparison with other commercial steel grades (Rodríguez Martínez et al., 2010b). The authors determined that the main cause behind such noticeable behavior was the considerable amount of martensite formed in the AISI 304 under dynamic loading (Fig. 1). This finding has major relevance since the martensitic transformation under impact loading is not usual in TRIP steels (Rodríguez Martínez et al., 2010a); the strong temperature increase associated with dynamic loadings tends to stabilize the austenite, avoiding the phase transformation.

The task is to evaluate the suitability of this constitutive description as predictive tool of the martensitic transformation occurring within the range of strain rates $\dot{\varepsilon} \geqslant 10 \mathrm{~s}^{1}$ (in which the material deformation process can be assumed adiabatic). Thus, the AISI 304 is presented as a good candidate for such a goal. Next, the constitutive model parameters are identified.

\section{Identification of the constitutive model parameters for the AISI 304 steel}

The identification procedure is split into two parts:

- Identification of the material parameters involved in the strain hardening/softening definition of the single phases, Eq. (44) (i. e. determination of the strain, rate and temperature sensitivity of the phases).

- Identification of the material parameters involved in the kinetics of the SIMT process, Eqs. (12), (15), (21), (22), (29) (31) and (34).

Table 1

Chemical composition of AISI 304 steel (\% weight).

\begin{tabular}{llllllll}
\hline $\mathrm{C}$ & $\mathrm{Mn}$ & $\mathrm{Cr}$ & $\mathrm{Ni}$ & $\mathrm{Mo}$ & $\mathrm{Cu}$ & $\mathrm{Si}$ & $\mathrm{Nb}$ \\
\hline 0.06 & 1.54 & 18.47 & 8.30 & 0.30 & 0.37 & 0.48 & 0.03 \\
\hline
\end{tabular}




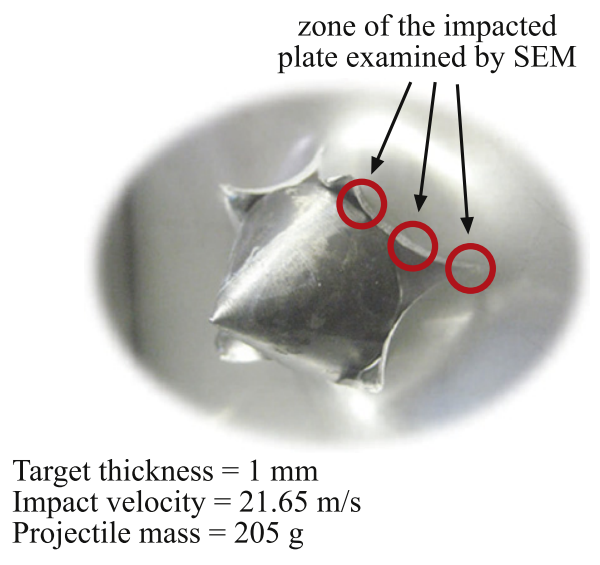

(a)

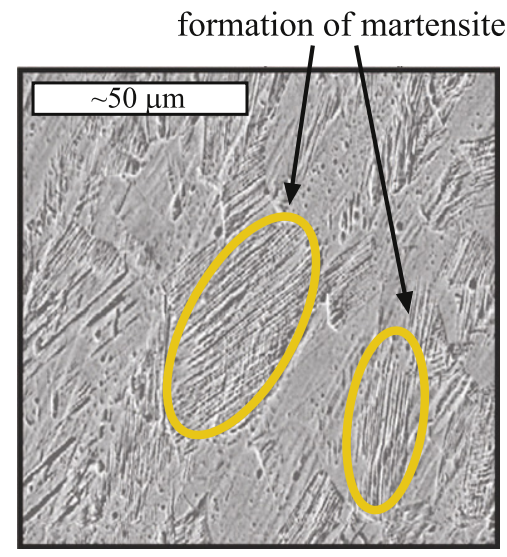

(b)

Fig. 1. (a) Perforation of an AISI 304 steel sheet by a non-deformable conical projectile (Rusinek et al., 2011). (b) SEM micrography of an AISI 304 steel sheet subjected to perforation by a non-deformable conical projectile (Rusinek et al., 2011).

\subsection{Identification of the material parameters involved in the mechanical behavior of the phases}

Identification of the strain, rate and temperature sensitivity of the phases is supported by the experimental data reported in Rodríguez Martínez et al. (2011) and Huang et al. (1989). The mechanical behavior of each phase is modified by the alloy ing elements and by the interaction between phases. Thus, strain hardening of a given phase may depend on the specific material considered. For a particular solid phase, the literature shows quite different behaviors. For such a problem to be avoided, the samples used in this work to determine the mechanical response of the phases and the specimens used to val idate the constitutive model (see Section 7) are obtained from the same steel sheet.

Thus, the stress strain curves of austenite and martensite provided by Rodríguez Martínez et al. (2011) are the basis for the calibration of the work hardening parameters. Strain hardening curves of the phases were obtained from in situ tensile tests. This type of tensile testing consists of mounting the sample in a tensile micromachine (Pesci et al., 2006) which is di rectly placed under a PROTO goniometer. Using X Rays Diffraction (XRD) technique, the stress was determined in each phase during the course of plastic deformation. The range of strain rate covered in such tests was $10^{5} \leqslant \dot{\varepsilon} \leqslant 10^{3} \mathrm{~s}{ }^{1}$. This exper imental arrangement does not allow for dynamic testing. In fact, the authors are unaware of any experimental stress strain curves of single phases obtained under dynamic loading for a two phase material. Fitting the experimental data to Eq. (43) for austenite and martensite, the flow stress and strain hardening material parameters of both phases are thus obtained (Fig. 2).

In the case of austenite, according to the experiments, both flow stress level and work hardening are properly defined by applying Eq. (43), Fig. 2 a. However, it was not possible to measure the stress in martensite in the case of $\bar{\varepsilon} p<0.25$ because of the very low intensity of the corresponding diffraction peaks. For such a range of strains, the volume fraction of martensite appears to be quite reduced at low strain rates, certainly $f_{m}<5 \%$. This hampers a proper determination of the stress in mar tensite using XRD (Rodríguez Martínez et al., 2011). Therefore, an extrapolation of the available experimental data has been performed to the range $\bar{\varepsilon}^{p}<0.25$ in order to identify flow stress and work hardening parameters of martensite (Fig. 2 b).

The next step is to determine the rate and temperature sensitivity of each phase. As previously mentioned, it was not pos sible to perform in situ tensile tests for $\dot{\varepsilon}>10^{3} \mathrm{~s}{ }^{1}$. For such limitations to be avoided, the rate sensitivity of both phases is assumed to be identical to the rate sensitivity of the homogenized material. Using the experimental data reported in Rusinek et al. (2010), the rate sensitivity parameter in Eq. (44) is determined (identical value of the rate sensitivity parameter for both phases), Fig. 3 a. In the same manner, using the experimental data reported in Huang et al. (1989), the temperature sensi tivity parameter in Eq. (44) is determined (identical value of the temperature sensitivity parameter for both phases), Fig. 3 b.

The values of the material parameters involved in the strain, rate, and temperature dependency of the single phases are listed in Table 2. Conventional physical constants of steel can be determined from material handbooks, Table 3. Material den sity $\rho$, specific heat $c_{v}$ and thermal expansion coefficient $\alpha_{\theta}$ have been assumed constant since temperature dependence of these material parameters within the range $200<\theta<500 \mathrm{~K}$ is rather small as reported elsewhere (Kim et al., 2010; Shiue et al., 2004).

\subsection{Identification of the material parameters involved in SIMT kinetics}

The material parameters involved in the kinetics of the SIMT were partially identified following the work by Iwamoto and Tsuta (2002). In that work, the authors applied a constitutive model based on the work of Olson and Cohen (1975) for the 


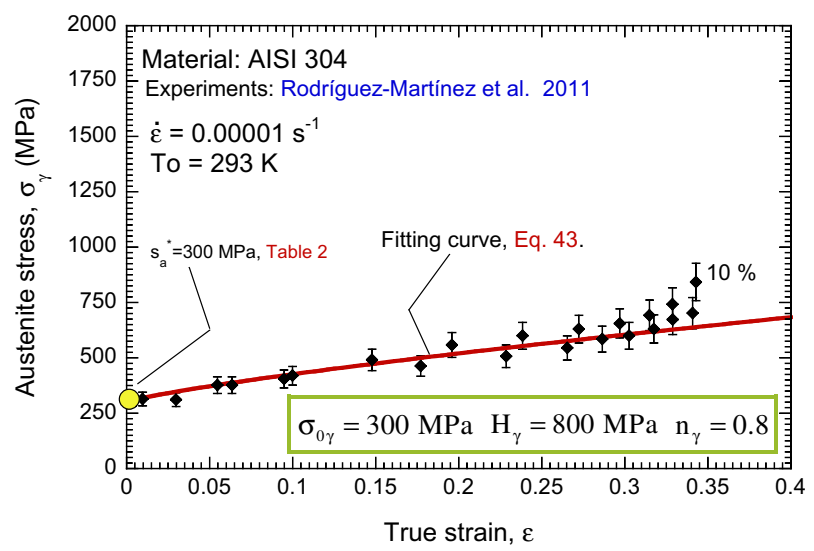

(a)

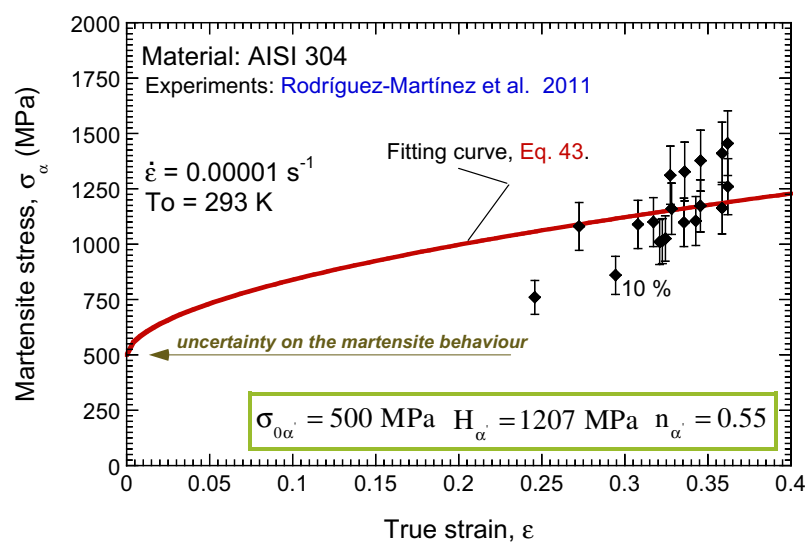

(b)

Fig. 2. Determination of the flow stress and strain hardening material parameters involved in Eq. (43) for (a) austenite and (b) martensite using the experimental data reported in Rodríguez-Martínez et al. (2011).

evaluation of the fracture toughness of the AISI 304 under static loading. Similarities in terms of formulation between the constitutive model used in the aforementioned work and the one developed in this paper were found. The values of some constants involved in Eqs. (21), (22), (30), (31) and (34) are taken directly from Iwamoto and Tsuta (2002) (Table 4).

Some other constants involved in Eqs. (12), (21), (29) and (30), basically those related to the temperature sensitivity of the transformation kinetics (therefore, directly tied to the temperature rise under dynamic loading which is not considered by Iwamoto and Tsuta (2002)), were determined based on the experimental observations reported by Rodríguez Martínez et al. (2011). The determination procedure can be summarized in the following three steps:

- A single curve $\sigma \quad \varepsilon$ drawn from a dynamic tensile test is taken as reference.

- A numerical model representing the aforementioned tensile test is developed.

- Identification of the material parameters $\alpha_{0}, \alpha_{1}, g_{0}, g_{1}$ involved in Eqs. (33) and (31) is phenomenologically conducted for the best correlation between numerical results and experiments.

The tensile experiment taken as reference (Rodríguez Martínez et al., 2011) was performed at $\dot{\varepsilon} \quad 200 \mathrm{~s}{ }^{1}$ and $T_{0}=293 \mathrm{~K}$ using a fast hydraulic machine. Then, the numerical model is developed; the geometry and dimensions of the specimen used in the simulations are shown in Fig. 4 a. The numerical sample coincides with the ones used in the experiments. Its impacted side is subjected to a constant velocity during the simulation. The movements of the impacted side are restricted to the axial direction and the opposite impact side is embedded. Such configuration idealizes the boundary conditions required for the test and guarantees the uniaxial tensile state in the active part of the specimen during loading. It must be noted that, in experiments, such an arrangement might be difficult to establish: the applied velocity may not be constant throughout the entire test, transversal displacements of the specimen may occur at the beginning of loading. However, this numerical configuration is suitable to impose a controlled level of deformation rate on the active part of the samples during the 


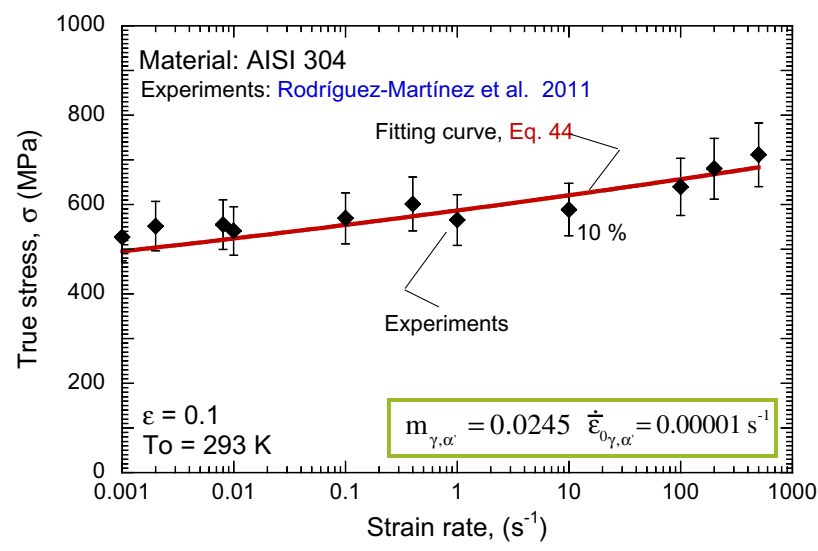

(a)

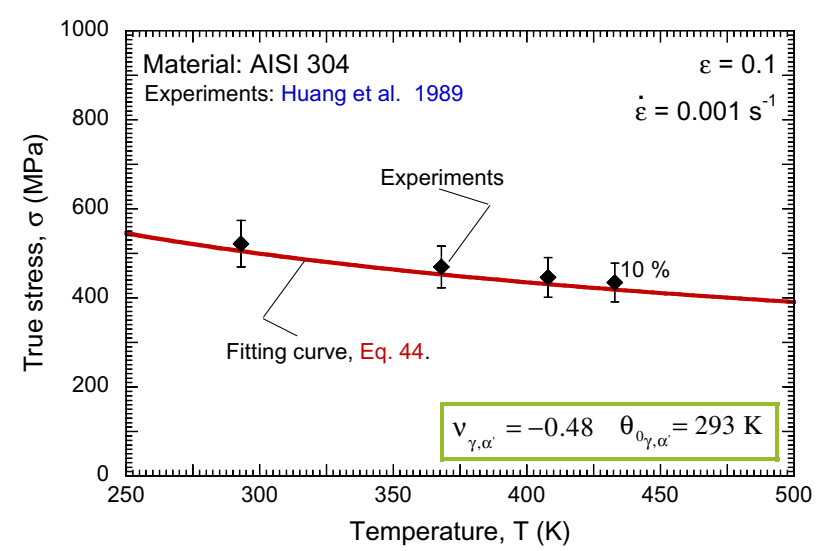

(b)

Fig. 3. Determination of the rate and temperature sensitivity material parameters involved into Eq. (44) using the experimental data reported in RodríguezMartínez et al. (2011) and Huang et al. (1989) for AISI 304 steel.

Table 2

Material parameters involved in Eqs. (44) and (51).

\begin{tabular}{lll}
\hline Symbol & Property and units & Value \\
\hline$\sigma_{0 \gamma}, \sigma_{0 \alpha^{\prime}}$ & Yield stress at reference strain rate and temperature & 300, \\
& (MPa), Eq. (44) & 500 \\
$H_{\gamma}, H_{\alpha^{\prime}}$ & Hardening modulus (MPa), Eq. (44) & 800, \\
& & 1207 \\
$n_{\gamma}, n_{\alpha^{\prime}}$ & Strain hardening exponent, Eq. (44) & 0.8, \\
& & 0.55 \\
$\varepsilon_{0 \gamma}, \varepsilon_{0 \alpha^{\prime}}$ & Reference strain rate (s ${ }^{1}$ ), Eq. (44) & 105 \\
$m_{\gamma}, m_{\alpha^{\prime}}$ & Rate sensitivity parameter, Eq. (44) & 0.0245 \\
$\theta_{0 \gamma}, \theta_{0 \alpha^{\prime}}$ & Reference temperature (K), Eq. (44) & 293 \\
$v_{\gamma}, v_{\alpha^{\prime}}$ & Temperature sensitivity parameter, Eq. (44) & -0.48 \\
$\eta^{q t}$ & Quinney-Taylor coefficient, Eq. (51) & 1 \\
\hline
\end{tabular}

simulations. Moreover, it should be highlighted that the consideration of a viscoplastic material model acts as a regulariza tion method for solving mesh dependent strain softening problems of plasticity (Glema et al., 2000). Rate dependent plas ticity implicitly introduces a length scale parameter into the boundary value problem, diffusing the localization region (Voyiadjis and Abed, 2006). This adequately helps to well pose the boundary value problem (Nemes and Eftis, 1993).

The mesh used consists of 556 eight node tri linear elements with reduced integration (C3D8R in ABAQUS notation). The mesh was derived from a mesh sensitivity analysis. It provides results in terms of stress strain curves and volume fraction of martensite (practically) independent of the mesh density. The integral viscoelastic approach available in ABAQUS/Explicit 
Table 3

Conventional physical constants for steel in Eqs. (36) and (51).

\begin{tabular}{lll}
\hline Symbol & Property and units & Value \\
\hline$\rho$ & Density $\left(\mathrm{kg} / \mathrm{m}^{3}\right)$, Eq. (51) & 7850 \\
$c_{v}$ & Specific heat $(\mathrm{J} / \mathrm{kgK})$, Eq. $(51)$ & 500 \\
$\alpha_{\theta}$ & Thermal expansion coefficient $\left(\mathrm{K}^{1}\right)$, Eq. (36) & $10^{5}$ \\
\hline
\end{tabular}

Table 4

The transformation kinetics parameters, Eqs. (12), (21), (22), (29)-(31), and (34).

\begin{tabular}{lll}
\hline Symbol & Property and units & Value \\
\hline$\Delta_{V}$ & Relative volume change due to transformation $\left(m^{3}\right)$, Eq. (22) & 0.02 Iwamoto and Tsuta (2002) \\
$A_{0}$ & Dimensionless material constant, Eq. (21) & 0.02 (Iwamoto and Tsuta, 2002) \\
$A_{1}$ & Dimensionless material constant, Eq. (21) & 0.02 (Iwamoto and Tsuta, 2002) \\
$s_{a}^{*}$ & Reference austenitic stress (MPa), Eq. (21) & 300 (Fig. 2-a) \\
$g_{0}$ & Dimensionless material constant, Eq. (30) & -30.00 \\
$g_{1}$ & Dimensionless material constant, Eq. (30) & 4.10 \\
$g_{2}$ & Dimensionless material constant, Eq. (30) & 76.10 (Iwamoto and Tsuta, 2002) \\
$M_{d}$ & Upper limit temperature for SIMT (K), Eq. (12) & 443 (Rodríguez-Martínez et al., 2011) \\
$M_{s}^{\sigma}$ & Lower limit temperature for SIMT (K), Eq. (12) & 173 (Rodríguez-Martínez et al., 2011) \\
$\alpha_{0}$ & Dimensionless material constant, Eq. (29) & 8.5 \\
$\alpha_{1}$ & Dimensionless material constant, Eq. (29) \\
$\beta_{0}$ & Dimensionless material constant, Eq. (34) & 0.59 \\
$n$ & Dimensionless material constant, Eq. (34) & 14.5 (Iwamoto and Tsuta, 2002) \\
$g$ & Dimensionless mean, Eq. (31) & 4.5 (Iwamoto and Tsuta, 2002) \\
$s_{g}$ & Standard deviation, Eq. (31) & -87 (Iwamoto and Tsuta, 2002) \\
\hline
\end{tabular}

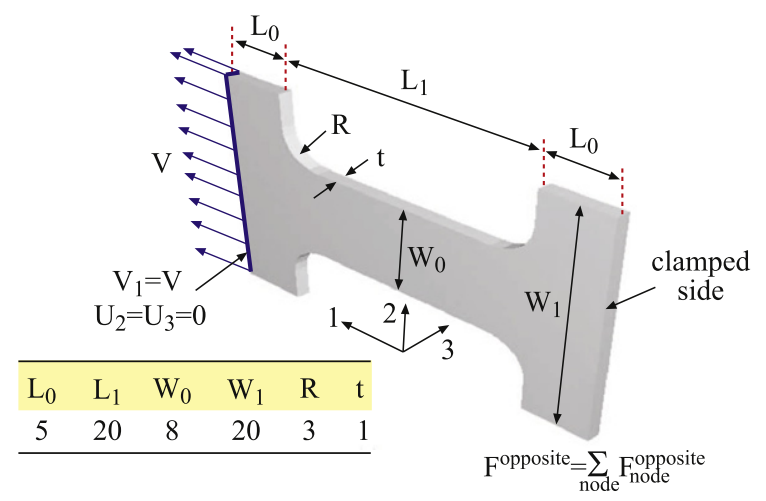

(a)

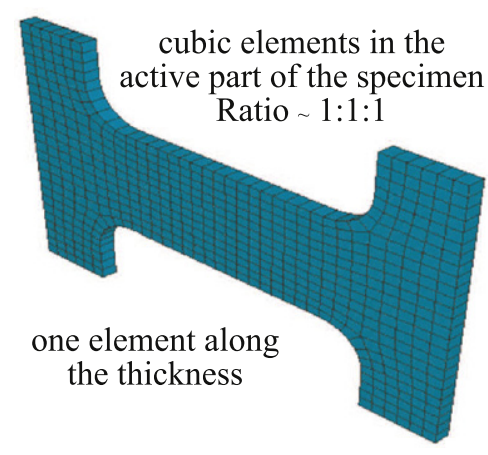

(b)

Fig. 4. (a) Geometry and dimensions ( $\mathrm{mm}$ ) of the specimen used in the numerical simulations. (b) Mesh configuration used in the numerical simulations.

has been used to prevent hourglass deformation modes; the scale factor used for all hourglass stiffnesses was chosen equal to one. According to the considerations reported by Zukas and Scheffer (2000) the active part of the specimen has been meshed using elements whose aspect ratio was close to $1: 1: 1\left(\approx 1 \times 1 \times 1 \mathrm{~mm}^{3}\right)$ (Fig. $\left.4 \mathrm{~b}\right)$; this leads to an average integra tion time step $\Delta t \approx 9 \quad 10^{8} \mathrm{~s}$.

Finally, experimental and numerical stress strain curves are compared. The values of the constants $\alpha_{0}, \alpha_{1}, g_{0}, g_{1}$ are ob tained for the best fitting condition (least square method), Fig. 5.

The complete set of constants involved in the kinetics of the martensitic transformation is listed in Table 4.

Once the constitutive model parameters are determined, the suitability of the constitutive description developed in this paper for predicting the martensitic transformation occurring in AISI 304 steel under dynamic loading is examined.

\section{Validation of the constitutive model: comparison between experiments and numerical simulations}

Validation of the computational model via simulation of structural impact processes (i.e. crash box structures impact, perforation of plates...) implies to consider complex shapes to reproduce the tested samples (i.e. strong bending and petal ling in the case of perforation of plates, multiple buckling in the case of crash box structures, etc...). This avoids potential 


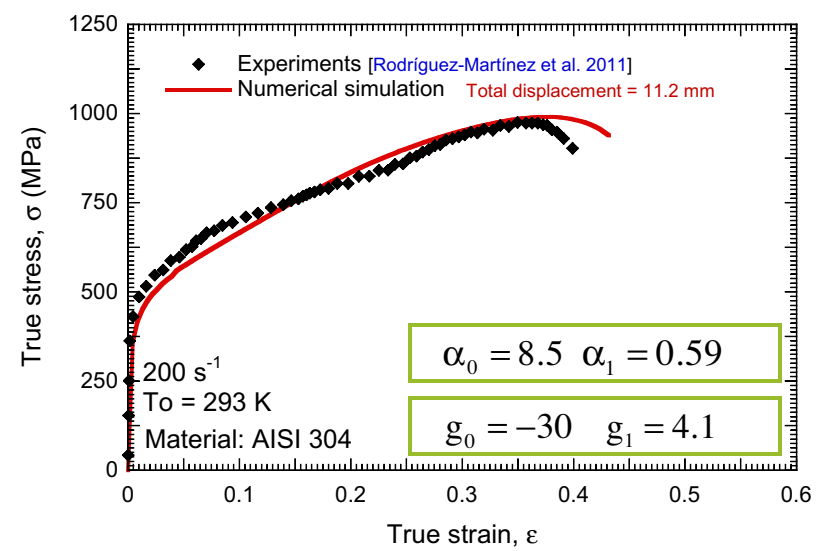

Fig. 5. Comparison between numerical predictions of the FE model and experiment performed at $\varepsilon \quad 200 \mathrm{~s}{ }^{1}$ for $T_{0}=293 \mathrm{~K}$ (Rodríguez-Martínez et al., 2011). The best correlation condition allows the identification of the parameters $\alpha_{0}, \alpha_{1}, g_{0}, g_{1}$.

measurements of the volume fraction of martensite in the tested specimens using regular experimental techniques such as XRD, which require flat surfaces for measuring (Rodríguez Martínez et al., 2010a,).

Therefore, for the validation, dynamic tensile tests were performed by the authors (different ones from those in volved in the calibration procedure) at strain rates within the range $10 \leqslant \dot{\varepsilon} \leqslant 500 \mathrm{~s}^{1}$ (Rodríguez Martínez et al., 2011). The surface of sheet tensile samples remains flat after testing. This allows the determination of the volume frac tion of martensite in the post mortem specimens using XRD and therefore enables validation concerning the transfor mation kinetics (Rodríguez Martínez et al., 2011). The range of loading rates covered during the experiments agrees with that expected in engineering applications such as crashworthiness (Rusinek et al., 2008), in which TRIP steels are frequently used.

Next, the numerical predictions are compared with experiments. The numerical model applied is the one illustrated in Fig. 4.

The validation of the constitutive model is conducted as follows:

- Experimental macroscopic stress strain curves measured within the range of strain rates $10 \leqslant \dot{\varepsilon} \leqslant 500 \mathrm{~s}{ }^{1}$ at room tem perature are compared with numerical predictions.

- Final volume fraction of martensite measured in samples tested within the range of strain rates $10 \leqslant \dot{\varepsilon} \leqslant 500 \mathrm{~s}{ }^{1}$ at room temperature is compared with the numerical predictions. Dynamic tests do not allow the time history of the evolution of the volume fraction of martensite to be measured over the course of plastic deformation.

Regarding the stress strain behavior of the material, Fig. 6 shows the good correlation between experiments and numer ical simulations. The constitutive model developed is able to define the flow stress as well as the strain hardening of the material for the loading conditions considered. In addition, the numerical simulations predict the saturation condition of the macroscopic stress strain curves in close agreement with experiments. It is well established that, in tensile tests, necking formation is basically tied to material flow stress level, strain hardening and strain rate sensitivity (Rodríguez Martínez, 2010). Only in the case of $\dot{\varepsilon} 500 \mathrm{~s}^{1}$, Fig. 6 c, a difference between experiments and simulation takes place. This discrep ancy may be related to perturbations on the testing velocity at the beginning of the experiment related to inertia effects fre quently observed in high rate tensile testing (Rusinek et al., 2005). Such perturbation of the applied velocity, which is not considered in the simulation, may induce strain rate history effects (structure evolution) on the material behavior (Klepaczko and Rezaig, 1996) that affect the final elongation of the sample.

According to the experimental observations, the simulations predict that austenite plays the role of the soft phase in the material deformation behavior, Fig. 7. It absorbs a major part of the energy supplied to the sample promoting the transfor mation. The strain as well as the strain rate of the austenite are quite close to the homogenized ones and much larger than those corresponding to the martensite. This behavior triggers the transformation which, as mentioned above, increases flow stress and strain hardening of the material, as illustrated in Fig. 7.

The SIMT process can be split into different stages, which can be defined as a function of the sample straining (Fig. 8).

- Stage I $\bar{\varepsilon}^{p} \leqslant 0.1$ : The numerical simulations predict the onset of the transformation at the very beginning of the loading process. This is consistent with the experimental evidence reported in Fig. 2 a. Low sample straining leads to the forma tion of martensite at the center of the active part of the specimen. Concerning the volume fraction of martensite, no rel evant differences are observed within the range of strain rates tested in the simulations. 


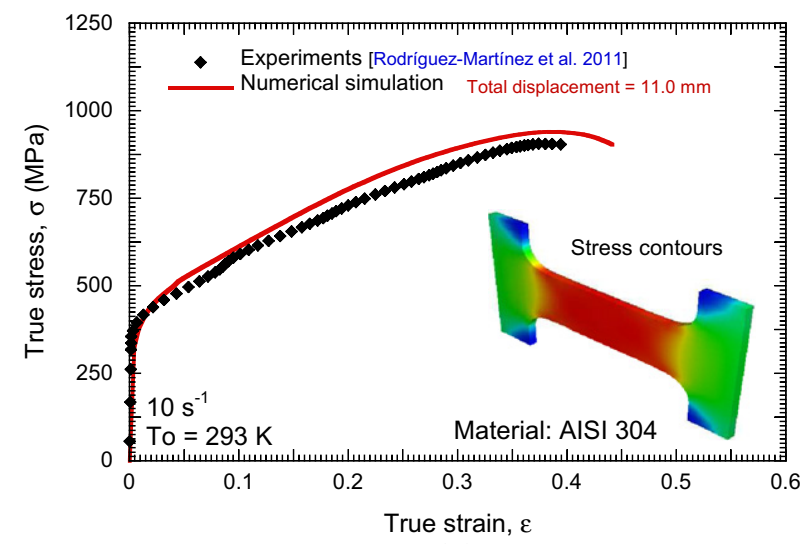

(a)

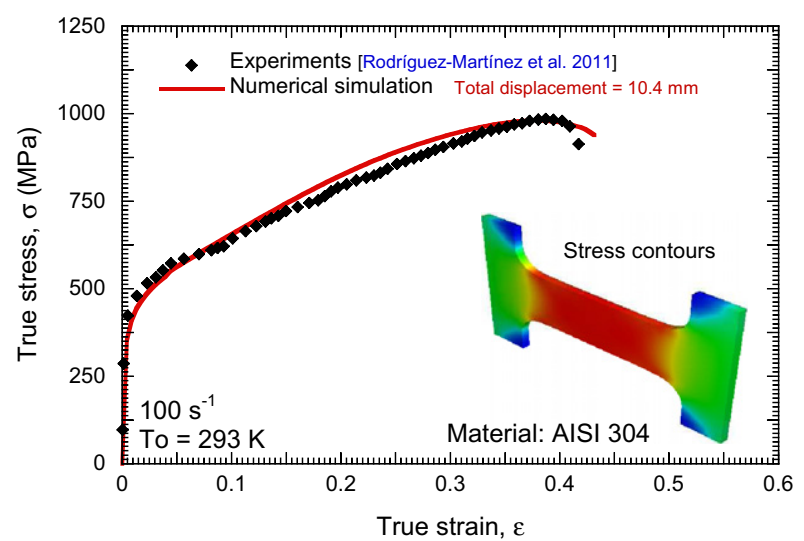

(b)

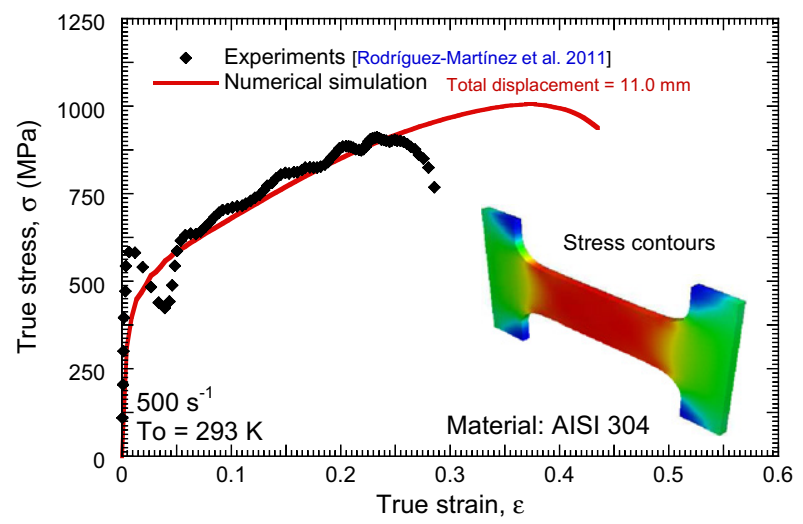

(c)

Fig. 6. Comparison between numerical predictions of the FE model and experiments at $T_{0}=293 \mathrm{~K}$ Rodríguez-Martínez et al. (2011). (a) $\varepsilon \quad 10 \mathrm{~s}{ }^{1}$, (b) $\varepsilon 100 \mathrm{~s}^{1}$, (c) $\varepsilon \quad 500 \mathrm{~s}^{1}$.

- Stage II $0.1<\bar{\varepsilon}^{p}<0.3$ : Greater sample straining tends to homogenize the deformation throughout the sample. Consequently, the numerical simulations predict a quite constant volume fraction of martensite throughout the active part of the specimen. At this stage, no relevant differences are observed concerning the numerical results for the range of strain rates tested.

- Stage III $\bar{\varepsilon}^{p} \geqslant 0.3$ : A higher strain level emphasizes the role played by the deformation rate on the SIMT process. At this stage, the numerical simulations predict a markedly decreasing volume fraction of martensite with an increasing loading rate, Fig. 8. The major role played by the temperature rise with respect to the SIMT process becomes evident. This obser vation agrees with the experimental observations reported by several authors (Rusinek and Klepaczko, 2009; Tomita and Iwamoto, 1995). 


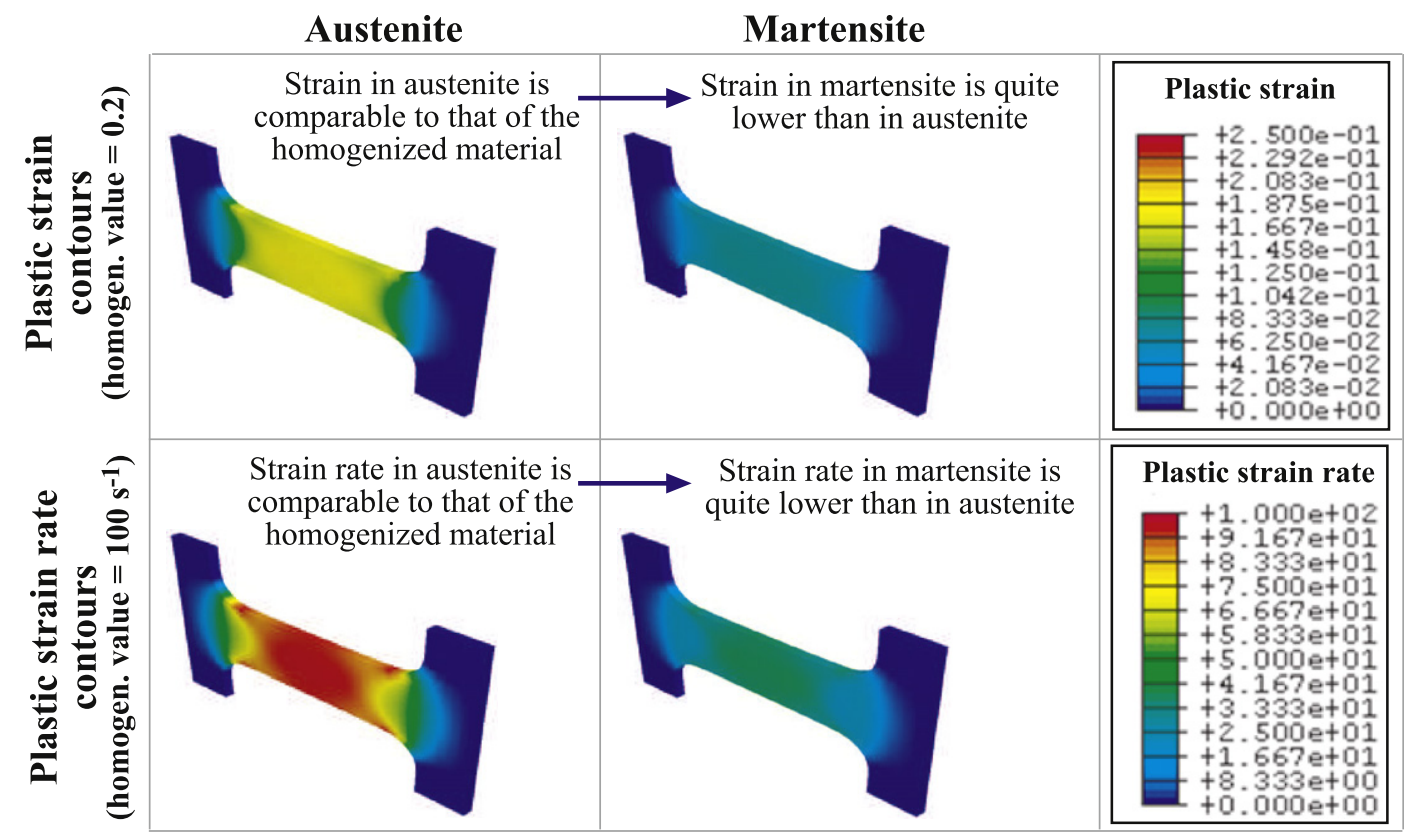

(a)

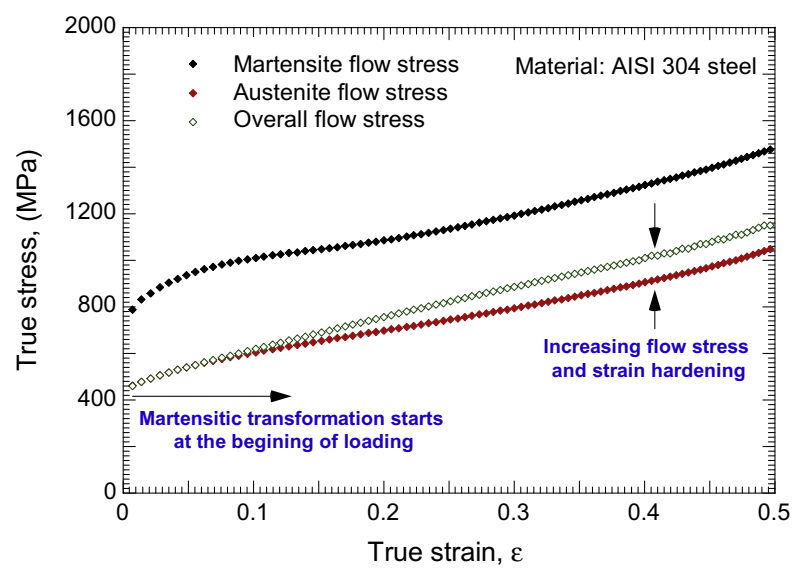

(b)

Fig. 7. (a) Contours of strain and strain rate for austenite and martensite, $\varepsilon^{p} \quad 0.2$ and $100 \mathrm{~s}{ }^{1}$. (b) Evolution of martensite flow stress, austenite flow stress and homogenized flow stress as a function of strain for $\varepsilon \quad 100 \mathrm{~s}^{1}$.

As a means of delving further into the previous analysis, Fig. 9 a illustrates numerical predictions of the volume fraction of martensite as a function of strain and strain rate. The aforementioned decrease in the volume fraction of martensite with increasing strain rate which takes place at large strains is clearly observed. It is noticeable that such a reduction of the vol ume fraction of martensite comes from very small variations on the material temperature increases, Fig. 9 b. The transfor mation kinetics is strongly temperature sensitive. Decreasing martensite volume fraction with increasing temperature at large strains is quantified from the simulations as $0.5\left(\% f_{m} / K\right)$.

Finally, the final volume fraction of martensite predicted by the simulations is compared with that experimentally mea sured (Fig. 10): good matching is found between numerical predictions and experiments.

The constitutive model proposed in this paper provides successful predictions of the mechanical response of the AISI 304 steel under dynamic loading. The formulation developed shows a good fit with the experimental results of the macroscopic flow stress behavior of the material as well as of the transformation kinetics. 


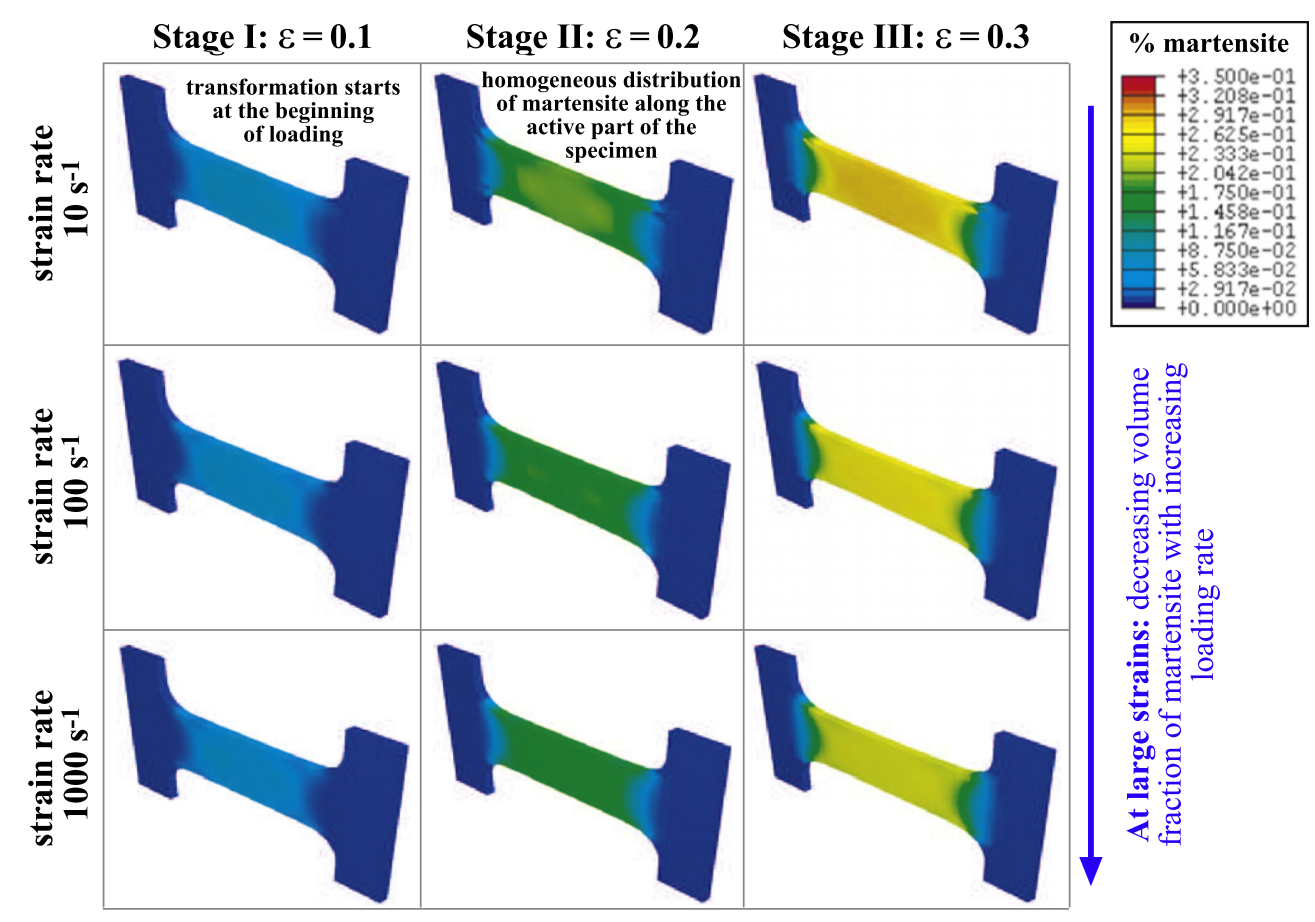

Fig. 8. Contours of the volume fraction of martensite for different loading rates and homogenized strain levels.

\section{Numerical analysis of the effect of the martensite transformation on the suitability of the material for energy absorption}

As discussed in the first section of this paper, metastable austenitic steels are frequently applied for manufacturing struc tural elements responsible for absorbing energy under impact. Once the constitutive model has been already validated, determinations can be made concerning the features of the model which play a main role in its ability to describe the dy namic behavior of TRIP steels.

\subsection{Effect of temperature on the martensite transformation}

The effect of temperature on the martensite transformation is examined. For this task, three different cases will be considered:

- Case I (the reference case): The material behavior is described by the parameter values listed in Tables 24 . This defines the behavior of the AISI 304 steel.

- Case II: The material does not exhibit SIMT (by application of the condition $\alpha_{0}=0$, Eq. (29)), Table 4 . This seeks to examine the role played by the martensitic transformation in the homogenized material behavior.

- Case III: The flow stress of the phases is defined as temperature independent by the application of the condition $v=0$, Eq. (44), Table 2. Solid phases behavior defined as temperature dependent is a new feature of the model developed in this paper. This proves relevant since temperature increase characterizes metal behavior under dynamic loading, leading to thermal softening of each phase.

An analysis of Fig. 11 reveals that Cases II and III deviate significantly from the experimental results. If the martensitic transformation is not considered, flow stress and strain hardening of the material are considerably underestimated. The opposite situation is found when the temperature sensitivity of the solid phases is not taken into account. Then, Case III, material stress level and work hardening are notably overestimated.

The differences concerning material flow level and strain hardening predicted by Cases I, II, and III can be quantified in terms of strain density energy absorbed by the sample. This is defined by the full integral of the stress strain curve up to saturation, as illustrated in Eq. (75).

$$
W_{a} \quad \int_{0}^{\varepsilon_{c}} \sigma d \varepsilon,
$$

where $\varepsilon_{c}$ is the strain at $d \sigma / d \varepsilon=0$. 


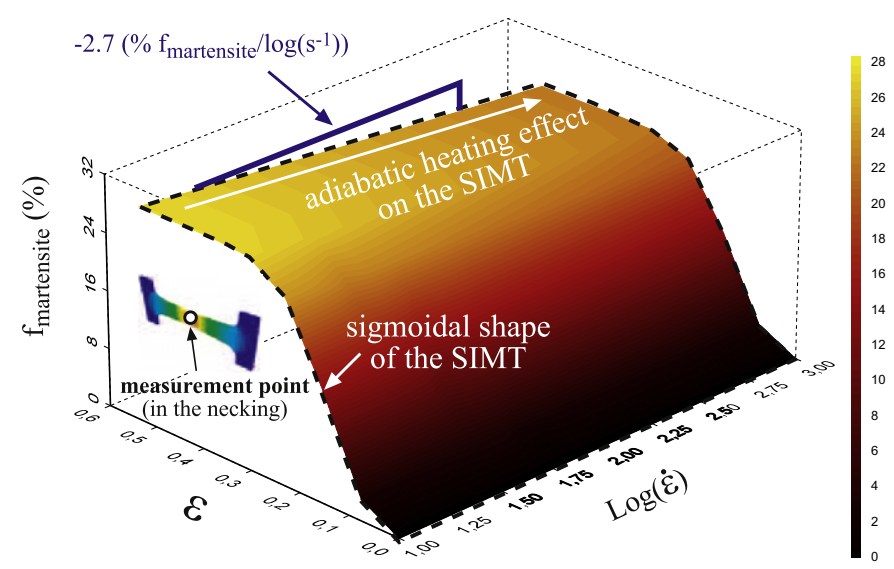

(a)

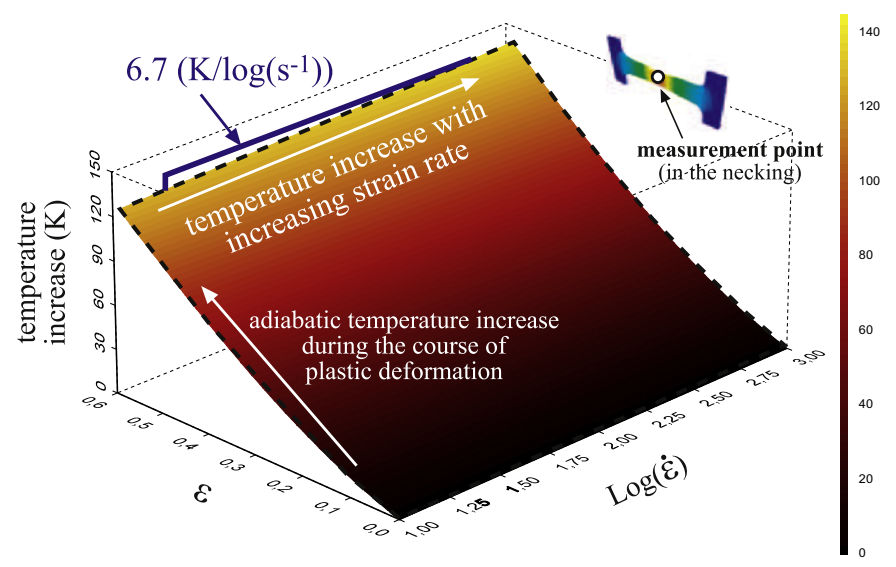

(b)

Fig. 9. (a) Numerical predictions of the volume fraction of martensite as a function of strain and strain rate. (b) Numerical predictions of the temperature rise as a function of strain and strain rate.

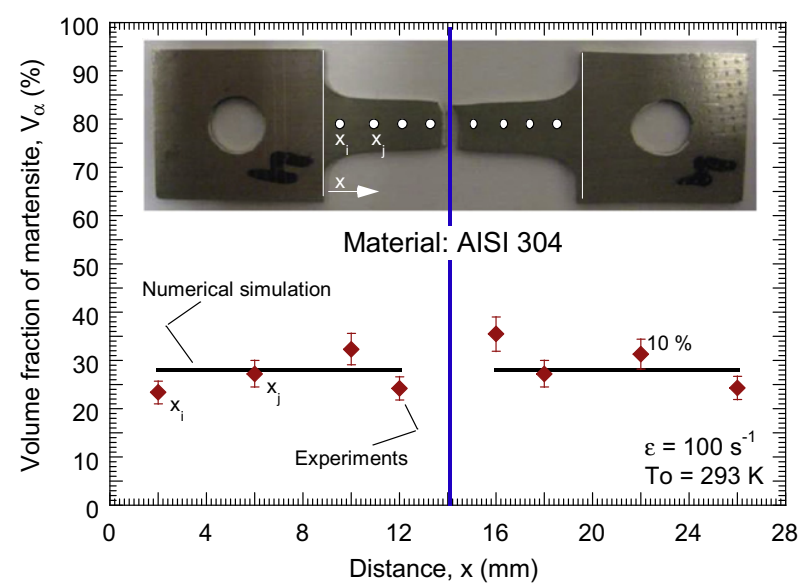

Fig. 10. Volume fraction of martensite in tensile specimens tested at $\varepsilon \quad 100 \mathrm{~s}^{1}$ and room temperature (Rodríguez-Martínez et al., 2011). Comparison between numerical predictions of the FE model and experiments.

Table 5 lists the values calculated from Eq. (75) in the cases considered, Fig. 11, but by percentage differences, tak ing the values plotted in the experimental curves as reference. The proposed constitutive modeling, Case I, determines properly the energy absorbed by the sample, the difference with experiments being less than $4 \%$ for the loading rates 


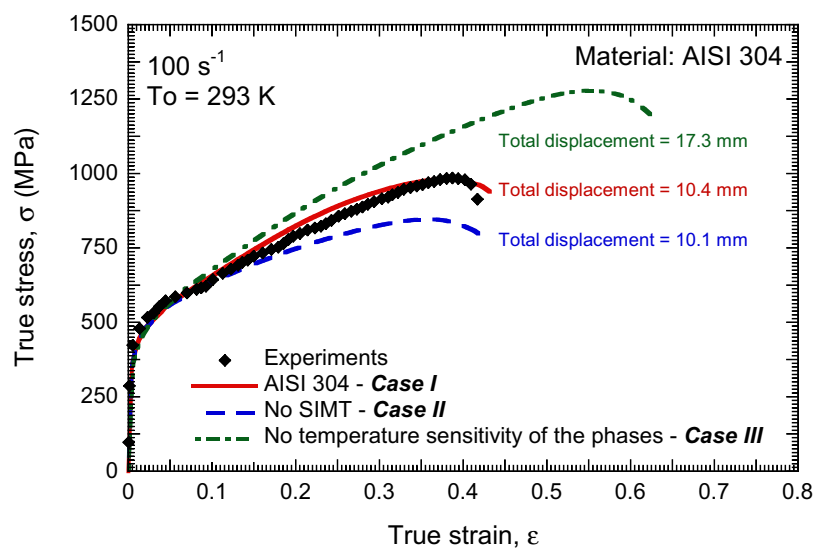

(a)

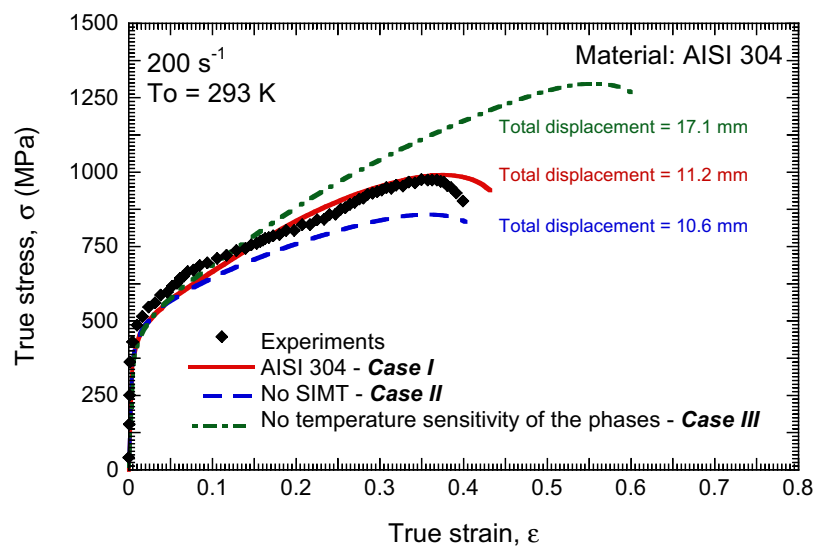

(b)

Fig. 11. Comparison between numerical predictions of the FE model and experiments at $T_{0}=293 \mathrm{~K}$ (Rodríguez-Martínez et al., 2011 ). (a) $\varepsilon \quad 100 \mathrm{~s}{ }^{1}$, (b) $\varepsilon \quad 200 \mathrm{~s}^{1}$.

Table 5

Percentage differences of the energy absorbed by the sample, taking as a reference the values obtained from the experimental curves.

\begin{tabular}{lllll}
\hline Loading rate $\left(\mathrm{s}^{1}\right)$ & Experimental values $\left(\mathrm{J} / \mathrm{m}^{3}\right)$ & Case I & Case II & Case III \\
\hline 100 & 292.4 & $3.3 \%$ & $-16.2 \%$ & $76.8 \%$ \\
200 & 296.9 & $3.3 \%$ & $-8.9 \%$ & $89.3 \%$ \\
\hline
\end{tabular}

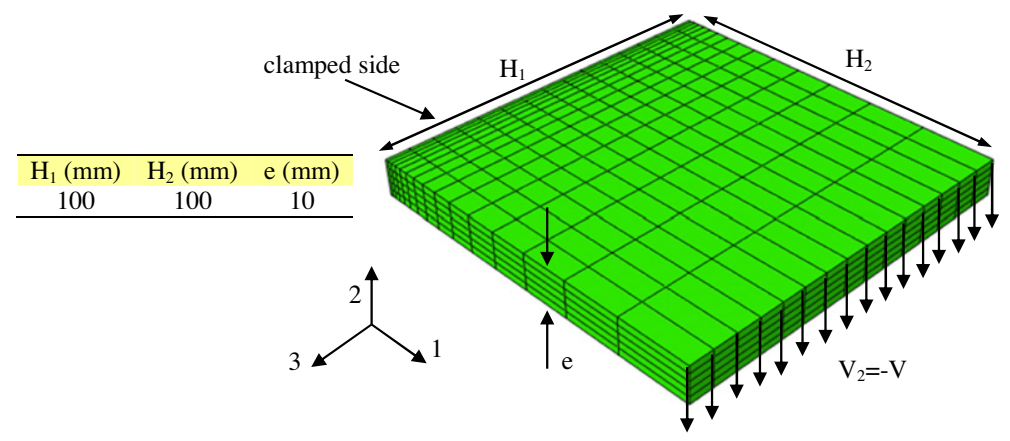

Fig. 12. Numerical configuration used to analyze the effect of stress state on martensite transformation. 
analyzed. If the martensitic transformation is not taken into account in the material modeling, Case II, the numerical predictions underestimate the energy absorbed by the sample. The role played by the SIMT on the suitability of the AISI 304 for building protection structures becomes evident. Finally, if the temperature sensitivity of the solid phases is not considered, Case III, the numerical predictions strongly overestimate the sample's energy absorption. Under dy namic loading conditions, temperature rise needs to be taken into account in the constitutive description of the phases. Indeed, it strongly affects the behavior of the homogenized material, determining its ability for energy absorption.

This analysis confirms that modeling of TRIP steels used for protection structures has to be conducted accurately. This task requires that the martensitic transformation occurring at high strain rates be taken into account together with the asso ciated thermodynamic irreversible process which converts plastic work into heat.

Next, the effect of stress state on martensite transformation is examined.

Table 6

Distance from the clamped side along the 1-direction for each pair of elements analyzed.

\begin{tabular}{ll}
\hline Element pair & Distance from the clamped side $(\mathrm{mm})$ \\
\hline 1 & 2.25 \\
2 & 11.00 \\
\hline
\end{tabular}

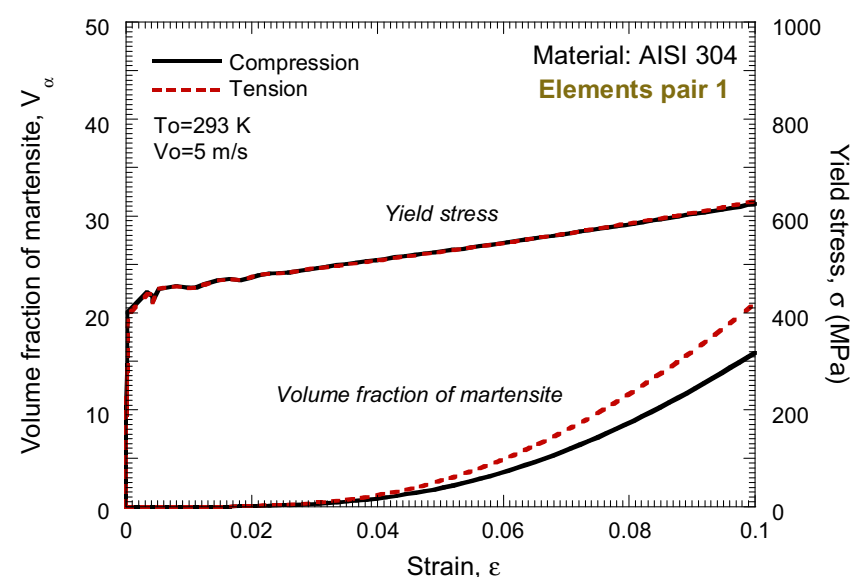

(a)

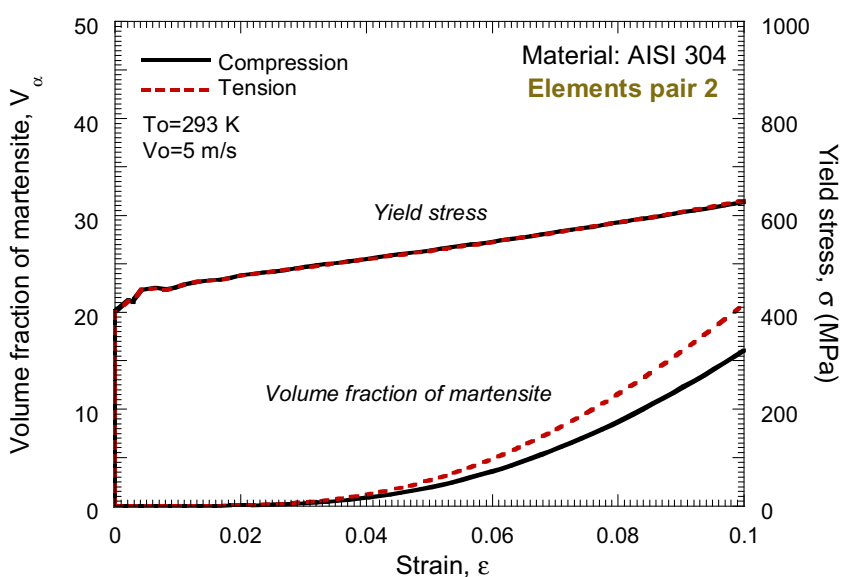

(b)

Fig. 13. Evolution of material yield stress and volume fraction of martensite as a function of the homogenized strain for $V_{1}=5 \mathrm{~m} / \mathrm{s}$, (a) elements pair 1 and (b) elements pair 2 . 

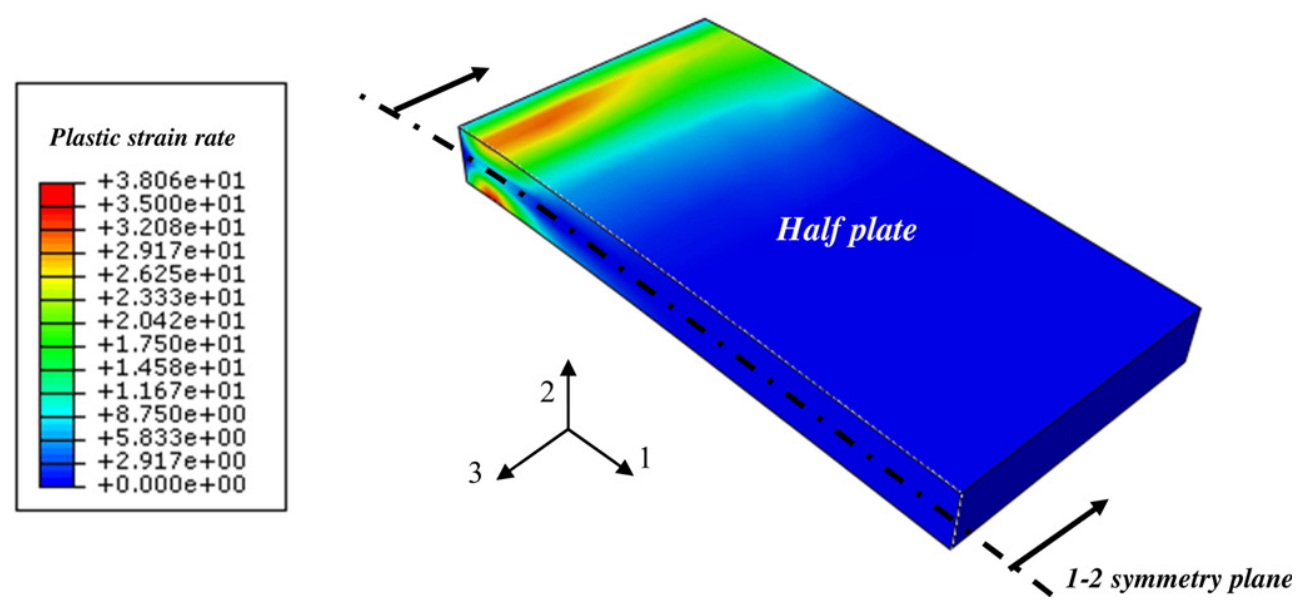

Fig. 14. Contours of strain rate for austenite. $V_{2}=10 \mathrm{~m} / \mathrm{s}, t=7.2 \cdot 10^{4} \mathrm{~s}$.

\subsection{Effect of the stress state on the martensite transformation}

In order to analyse the effect of stress state on the martensite transformation a numerical model is developed in ABAQUS/ Explicit (HKS, 2003). The geometry and dimensions of the specimen used in the simulations are shown in Fig. 12. Its im pacted side is subjected to a constant velocity during the simulation and the opposite impact side is embedded. Sides per pendicular to the clamped one (and therefore to the impacted side) are free of constraints. Thus the plate is subjected to bending inducing dominant tension at the top of the sample and dominant compression at the bottom. Two different impact velocities are considered, $V_{1}=5 \mathrm{~m} / \mathrm{s}$ and $V_{2}=10 \mathrm{~m} / \mathrm{s}$. The material behavior is described by the parameter values listed in Tables 24.

The mesh used consists of 1125 eight node tri linear elements with reduced integration, C3D8R in ABAQUS notation. 225 elements are placed in the 13 plane and 5 elements along the thickness of the plate ( 2 direction). The element size dimin ishes progressively from the impacted end to the clamped side, getting a reduction ratio 15:1 along the 1 direction. The min imum element size is $1.0 \times 2.0 \times 6.6 \mathrm{~mm}^{3}$, this leads to an average integration time step $\Delta t \approx 10{ }^{7} \mathrm{~s}$. The mesh was derived from a mesh sensitivity analysis. It provides results in terms of stress strain curves and volume fraction of martensite (prac tically) independent of the mesh density. Again, the integral viscoelastic approach available in ABAQUS/Explicit has been used to prevent hourglass deformation modes; the scale factor used for all hourglass stifnesses was chosen equal to one.

Two pairs of elements along the symmetry plane and at different distances from the clamped side are conveniently se lected, Table 6. One element of each pair is located at the top of the plate, the other one at the bottom.

Then the homogenized stress, the homogenized strain and the volume fraction of martensite are measured in the selected elements. Fig. 13 illustrates the results obtained for $V_{1}=5 \mathrm{~m} / \mathrm{s}$ and for both elements pairs. The yield stress evolution as a function of the homogenized strain practically coincides for both elements; however the martensite formation is larger in the case of the element subjected to (dominant) tension. This is consistent with the experimental evidence reported else where (Young, 1988; Lebedev and Kosarchuk, 2000; Turteltaub and Suiker, 2005).

Next, contours of strain rate for austenite are shown for $V_{2}=10 \mathrm{~m} / \mathrm{s}$ at a given time, Fig. 14 . It can be seen that the strain rate markedly varies from the clamped end to the free end and from the top part to the bottom. As expected, maximum strain rate level is located close to the embedded site where larger flow stress level takes place.

This analysis attempts to provide further validation of the constitutive model ability for describing the mechanical behav iour of the material under complex loading conditions involving three dimensional states of stress where relevant strain and strain rate gradients may occur.

\section{Conclusions}

The increasing use of metastable austenitic steels in the industry for crash applications, as well as the high strain rates reached by these alloys during machining and high speed forming, motivates the analysis of their behavior under dynamic loading. Strain hardening of these grades is strongly coupled to their ability to transform the austenitic phase to a harder martensitic phase. This process is markedly influenced by temperature, which is known to increase at high rates of defor mation. This reflects the value of considering thermal effects in the analysis of metastable austenitic steels under impact conditions.

Most works available in the literature are restricted to the analysis of strain induced martensitic transformation (SIMT) under isothermal conditions. The present paper complements these former works by an analysis of the role played by tem perature in the SIMT process at high strain rates. The analysis is based on the proposal of a constitutive model for two phase 
steels exhibiting SIMT, which considers the effect of temperature adiabatic increase, both in the kinetics of the SIMT and in the softening of the solid phases. The proper development of the constitutive model also required the definition of a system atic procedure for the identification of the material parameters, and a validation with experimental results, both performed for the AISI 304 grade. The results reveal the necessity of considering thermal effects for a suitable definition of martensite formation, strain hardening, and energy absorption at high strain rates.

\section{Acknowledgements}

The researchers of the University Carlos III of Madrid are indebted to the Comunidad Autónoma de Madrid (Project CCG10 UC3M/DPI 5596)) and to the Ministerio de Ciencia e Innovación de España (Project DPI/2008 06408) for the financial support received which allowed conducting part of this work.

The authors express their thanks to Mr. Philippe and Mr. Tobisch from the company Zwick for the facilities provided to perform the tensile tests at high strain rates.

\section{References}

Andersson, R., 2005. Deformation characteristics of stainless steels. Ph.D. Thesis, Lulea University of Technology, Sweden.

Angel, T., 1954. Formation of martensite in austenitic stainless steels. Effects of deformation, temperature and composition. Journal of Iron and Steel Institute 177, 165-174.

Bertram, A., 1999. An alternative approach to finite plasticity based on material isomorphisms. International Journal of Plasticity 15 , 353-374.

Brunig, M., Gerke, S., 2011. Simulation of damage evolution in ductile metals undergoing dynamic loading conditions. International Journal of Plasticity. doi:10.1016/j.ijplas.2011.02.003.

Cherkaoui, M., Berveiller, M., Lemoine, X., 2000. Couplings between plasticity and martensitic phase transformation: overall behavior of polycrystalline trip steels. International Journal of Plasticity 16, 1215-1241.

Cherkaoui, M., Berveiller, M., Sabar, H., 1998. Micromechanical modeling of martensitic transformation induced plasticity (TRIP) in austenitic single crystals. International Journal of Plasticity 14, 597-626.

Curtze, S., Kuokkala, V.T., Hokka, M., Peura, P., 2009. Deformation behavior of trip and dp steels in tension at different temperatures over a wide range of strain rates. Materials Science and Engineering A 507, 124-131.

Dachkovski, S., Böhm, M., 2004. Finite thermoplasticity with phase changes based on isomorphisms. International Journal of Plasticity $20,323-334$.

Dan, W.J., Li, S.H., Zhang, W.G., Lin, Z.Q., 2008. The effect of strain-induced martensitic transformation on mechanical properties of trip steel. Materials and Design 29, 604-612.

De, A.K., Speer, J.G., Matlock, D.K., Murdock, D.C., Mataya, M.C., Comstock, R.J., 2006. Deformation-induced phase transformation and strain hardening in type 304 austenitic stainless steel. Metallurgical and Material Transactions A 37, 1875-1886.

Delannay, L., Lani, F., Jacques, P.J., 2005. Simulation of deep-drawing of TRIP-assisted multiphase steel based on a micro-macro modelling. In: Boudeau, N. (Ed.), 24th International deep-drawing research group Congress. Kluwer, pp. 1-10.

Doghri, I., 2000. Mechanics of Deformable Solids: Linear and Nonlinear, Analytical and Computational Aspects. Springer, Berlin.

Egner, H., Skoczén, B.B., 2010. Ductile damage development in two-phase metallic materials applied at cryogenic temperatures. International Journal of Plasticity 26, 488-506.

Farrokh, B., Khan, A.S., 2009. Grain size, strain rate, and temperature dependence of flow stress in ultra-fine grained and nanocrystalline Cu and Al: synthesis, experiment, and constitutive modeling. International Journal of Plasticity 25, 715-732.

Fisher, F.D., Reisner, G., Werner, E., Tanaka, K., Cailletaud, K., Antretter, T., 2000. A new view on transformation induced plasticity (TRIP). International Journal of Plasticity 16, 723-748.

Garion, C., Skoczén, B., 2002. Modeling of plastic strain induced martensitic transformation for cryogenic applications. Journal of Applied Mechanics 69, 755-762.

Garion, C., Skoczén, B., Sgobba, S., 2006. Constitutive modelling and identification of parameters of the plastic strain-induced martensitic transformation in 316L stainless steel at cryogenic temperatures. International Journal of Plasticity 22, 1234-1264.

Glema, A., Lodygowski, T., Perzyna, P., 2000. Interaction of deformation waves and localization phenomena in inelastic solids. Computers Methods in Applied Mechanics and Engineering 183, 123-140.

Greenwood, G.W., Johnson, R.H., 1965. The deformation of metals under small stresses during phase transformation. Proceeding of the Royal Society A283, 403-422.

Hagege, B., 2004. Simulation du comportement mécanique des milieux fibreux en grandes transformations: application aux renforts tricotés. Ph.D. Thesis, ENSAM, Paris.

Hallberg, H., Hakansson, P., Ristinmaa, M., 2007. A constitutive model for the formation of martensite in austenitic steels under large strain plasticity. International Journal of Plasticity 23, 1213-1239.

Han, H.N., Lee, C.G., Oh, C., Lee, T., Kim, S., 2004. A model for deformation behavior and mechanically induced martensitic transformation of metastable austenitic steel. Acta Materialia 52, 5203-5214.

Hänsel, A.H., Hora, P., Reissner, J., June 1998. Description of straininduced martensitic phase transformation in metastable austenitic steels for the simulation of deep drawing processes at non isothermal conditions. in: 20th Biennial IDDRG Congress. Brussels, Belgium, pp. 387-398.

Hecker, S.S., Stout, M.G., Staudhammer, K.P., Smith, J.L., 1982. Effects of strain and strain rate on deformation-induced transformation in 304 stainless steel. Part I: magnetic measurements and mechanical behaviourl. Metallurgical Transactions A 13A, 619-626.

HKS, 2003. Abaqus Explicit v6.4 User's Manual, version 6.4 Edition. ABAQUS Inc., Richmond, USA.

Huang, G.L., Matlock, D.K., Krauss, G., 1989. Martensite formation, strain rate sensitivity, and deformation behaviour of type 304 stainless steels sheet. Metallurgical Transactions 20A, 1239-1246.

Hughes, T.J.R., Winget, J., 1980. Finite rotation effects in numerical integration of rate constitutive equations arising in large-deformation analysis. International Journal for Numerical Methods in Engineering 15, 1862-1867.

Iwamoto, T., Tsuta, T., 2002. Computational simulation on deformation behavior of CT specimens of TRIP steel under mode i loading for evaluation of fracture toughness. International Journal of Plasticity 11, 1583-1606.

Iwamoto, T., Tsuta, T., Tomita, Y., 1998. Investigation of deformation mode dependence of strain-induced martensitic transformation in trip steels and modelling of transformation kinetics. International Journal of Mechanical Sciences 40, 173-182.

Khan, A.S., Huang, S., 1995. Continuum Theory of Plasticity. John Wiley \& Sons, New York.

Khan, A.S., Kazmi, R., Farrokh, B., Zupan, M., 2007. Effect of oxygen content and microstructure on the thermo-mechanical response of three Ti-6Al-4V alloys: experiments and modeling over a wide range of strain-rates and temperatures. International Journal of Plasticity 23 , $1105-1125$.

Khan, A.S., Meredith, C.S., 2010. Thermo-mechanical response of Al 6061 with and without equal channel angular pressing (ECAP). International Journal of Plasticity 26, 189-203. 
Khan, A.S., Suh, Y.S., Kazmi, R., 2004. Quasi-static and dynamic loading responses and constitutive modeling of titanium alloys. International Journal of Plasticity 20, 2233-2248.

Kim, K., Lee, J., Chou, H., 2010. Analysis of pulsed Nd:YAG laser welding of AISI 304 steel. Journal of Mechanical Science and Technology 24, $2253-2259$.

Klepaczko, J.R., 1987. A practical stress-strain-strain rate-temperature constitutive relation of the power form. Journal of Mechanical Working Technology $15,143-165$.

Klepaczko, J.R., Rezaig, B., 1996. A numerical study of adiabatic shear banding in mild steel by dislocation mechanics based constitutive relations. Mechanics of Materials 24, 125-139.

Kubler, R.F., Berveiller, M., Buessler, P., 2011. Semi phenomenological modelling of the behavior of TRIP steels. International Journal of Plasticity 27, 299327.

Kuchniki, S.N., Radovitzki, R.A., Cuitiño, A.M., 2008. An explicit formulation for multiscale modeling of bcc metals. International Journal of Plasticity 24, 2173-2191.

Langdon, G.S., Schleyer, G.K., 2005a. Inelastic deformation and failure of profiled stainless steel blast wall panels. Part I: experimental investigations. International Journal of Impact Engineering 31, 341-369.

Langdon, G.S., Schleyer, G.K., 2005b. Inelastic deformation and failure of profiled stainless steel blast wall panels. Part II: analytical modelling considerations. International Journal of Impact Engineering 31, 371-399.

Langdon, G.S., Schleyer, G.K., 2006. Deformation and failure of profiled stainless steel blast wall panels. Part III: finite element simulations and overall summary. International Journal of Impact Engineering 32, 988-1012.

Leal, R.H., 1984. Transformation toughening of metastable austenitic steels. Ph.D. Thesis, MIT, Cambridge, Massachusetts.

Lebedev, A.A., Kosarchuk, V.V., 2000. Influence of phase transformations on the mechanical properties of austenitic stainless steels. International Journal of Plasticity 16, 749-767.

Lee, M.G., Kim, S.J., Han, H.N., 2010. Crystal plasticity finite element modeling of mechanically induced martensitic transformation (mimt) in metastable austenite. International Journal of Plasticity 26, 688-710.

Liang, R., Khan, A.S., 1999. A critical review of experimental results and constitutive models for bcc and fcc metals over a wide range of strain rates and temperatures. International Journal of Plasticity 15, 963-980.

Lichtenfeld, J.A., Mataya, M., Tyne, C.J.V., 2006. Effect of strain rate on stress-strain behavior of alloy 309 and 3041 austenitic stainless steel. Metallurgical and Materials Transactions A 37A, 147-161.

Love, B.M., Batra, R.C., 2006. Determination of effective thermomechanical parameters of a mixture of two elastothermoviscoplastic constituents. International Journal of Plasticity 22, 1026-1061.

Magee, C., 1966. Transformation kinetics, microplasticity and ageing of martensite in fe-3lni. Ph.D. Thesis, Carnegie Institute of Technologie University, Pittsburgh, PA.

Mahnken, R., Schneidt, A., Antretter, T., 2009. Macro modelling and homogenization for transformation induced plasticity of a low-alloy steel. International Journal of Plasticity 25, 183-204.

Mercier, A., Molinari, A., 2009. Homogenization of elastic-viscoplastic heterogeneous materials: Self-consistent and mori-tanaka schemes. International Journal of Plasticity 25, 1024-1048.

Mercier, S., Molinari, A., 2004. Analysis of multiple necking in rings under rapid radial expansion. International Journal of Impact Engineering 30, 403-419.

Mertinger, V., Nagy, E., Tranta, F., Sólyom, J., 2008. Strain-induced martensitic transformation in textured austenitic stainless steels. Materials Science and Engineering A, 718-722.

Miguélez, H., Zaera, R., Molinari, A., Cheriguene, R., Rusinek, A., 2009. Residual stresses in orthogonal cutting of metals: the effect of thermomechanical coupling parameters and of friction. Journal of Thermal Stresses 21, 269-289.

Miller, M.P., McDowell, D.L., 1996. Modelling large strain multiaxial effects in fcc polycrystals. International Journal of Plasticity $12,875-902$.

Molinari, A., Musquar, C., Sutter, G., 2002. Adiabatic shear banding in high speed machining of Ti-6Al-4V: experiments and modeling. International Journal of Plasticity 18, 443-459.

Nemes, J.A., Eftis, J., 1993. Constitutive modelling on the dynamic fracture of smooth tensile bars. International Journal of Plasticity 9, $243-270$.

Oberste-Brandenburg, C., Bruhns, O.T., 2004. A tensorial description of the transformation kinetics of the martensitic phase transformation. International Journal of Plasticity 20, 2083-2109.

Oliver, S., Jones, T.B., Foularis, G., 2007. Dual phase versus trip strip steels: microstructural changes as a consequence of quasi-static and dynamic tensile testing. Materials Characterization 58, 390-400.

Olson, G.B., Azrin, M., 1978. Transformation behavior of trip steels. Metallurgical and Materials Transactions A 9 (5), $713-721$.

Olson, G.B., Cohen, M., 1975. Kinetics of strain-induced martensitic nucleation. Metallurgical Transactions A 6A, $791-795$.

Papatriantafillou, I., Agoras, M., Aravas, N., Haidemenopoulos, G., 2006. Constitutive modeling and finite element methods for trip steels. Computer Methods in Applied Mechanics and Engineering 195, 5094-5114.

Papatriantafillou, I., Aravas, N., Haidemenopoulos, G., 2004. Finite element modelling of trip steels. Steel Research International 75, $732-738$.

Pesci, R., Inal, K., Berveiller, S., Patoor, E., Lecomte, J.S., Eberhardt, A., 2006. Inter- and intragranular stress determination with kossel microdiffraction in a scanning electron microscope. Materials Science Forum, 109-114.

Petein, A., 2006. On the interactions between strain-induced phase transformations and mechanical properties in Fe-Mn-Si-al steels and fe-ni-cr austenitic stainless steels. Ph.D. Thesis, Louvain-la-Neuve, Belgium.

Petit, B., Gey, N., Cherkaoui, M., Bolle, B., Humbert, M., 2007. Deformation behavior and microstructure/texture evolution of an annealed 304 AISI stainless steel sheet. experimental and micromechanical modeling. International Journal of Plasticity 23, 323-341.

Rodríguez-Martínez, J.A., 2010. Advanced constitutive relations for modeling thermoviscoplastic behaviour ofmetallic alloys subjected to impact loading. Ph.D. thesis, University Carlos III of Madrid-University Paul Verlaine of Metz/ENIM 2010.

Rodríguez-Martínez, J.A., Pesci, R., Rusinek, A., 2011. Experimental study on the martensitic transformation in AISI 304 steel sheets subjected to tension under wide ranges of strain rate at room temperature. Materials Science and Engineering: A 528, 5974-5982.

Rodríguez-Martínez, J.A., Pesci, R., Rusinek, A., Arias, A., Zaera, R., Pedroche, D.A., 2010a. Thermo-mechanical behaviour of TRIP 1000 steel sheets subjected to low velocity perforation by conical projectiles at different temperatures. International Journal of Solids and Structures $47,1268-1284$.

Rodríguez-Martínez, J.A., Rusinek, A., Pesci, R., 2010b. Experimental survey on the behaviour of AISI 304 steel sheets subjected to perforation. Thin-Walled Structures 48, 966-978.

Rusinek, A., Klepaczko, J.R., 2009. Experiments on heat generated during plastic deformation and stored energy for TRIP steels. Materials and Design 30, 3548.

Rusinek, A., Rodríguez-Martínez, J.A., Pesci, R., Capelle, J., 2010. Experimental characterisation and modelling of the thermo-viscoplastic behaviour of steel AISI 304 within wide ranges of strain rate at room temperature. Journal of Theoretical and Applied Mechanics 48, 1027-1042.

Rusinek, A., Rodríguez-Martínez, J.A., Pesci, R., Zaera, R., Fernández-Sáez, J.A., 2011. Internal report ENIM/UC3M: martensitic transformation in AISI 304 sheets subjected to perforation.

Rusinek, A., Zaera, R., Forquin, P., Klepaczko, J.R., 2008. Effect of plastic deformation and boundary conditions combined with elastic wave propagation on the collapse site of a crash box. Thin-Walled Structures 46, 1143-1163.

Rusinek, A., Zaera, R., Klepaczko, J.R., Cheriguene, R., 2005. Analysis of inertia and scale effects on dynamic neck formation during tension of sheet steel. Acta Materialia 53, 5387-5400.

Shiue, R.K., Chang, C.T., Young, M.C., Tsay, L.W., 2004. The effect of residual thermal stresses on the fatigue crack growth of laser-surface-annealed AISI 304 stainless steel. Part I: computer simulation. Materials Science and Engineering A 364, 101-108. 
Sideridis, E., Kytopoulos, V.N., Kyriazi, E., Bourkas, G., 2005. Determination of thermal expansion coefficient of particulate composites by the use of a triphase model. Composites Science and Technology 65, 909-919.

Simo, J.C., Hughes, T.J.R., 1998. Computational Inelasticity. Springer, New York.

Stringfellow, R.G., Parks, D.M., Olson, G.B., 1992. A constitutive model for transformation plasticity accompanying strain-induced martensitic transformations in metastable austenitic steels. Acta Metallurgica et Materialia 40 (7), 1703-1716.

Suquet, P., 1995a. Overall properties of nonlinear composites: a modified secant moduli theory and its link to Ponte Castañeda's nonlinear variational procedure. Comptes Rendus de 1 Academie des Sciences Paris, Sèrie II b 320, 563-571.

Suquet, P., 1995b. Overall properties of nonlinear composites: secant moduli theories and variational bounds. In: Markov, K.Z. (Ed.), Continuum Models and Discrtete Systems, Proceedings of 8th International Symposium. World Scientific Publishing Company, pp. $290-299$.

Suquet, P., 1996. Overall properties of nonlinear composites: remarks on secant and incremental formulations. In: Pineau, A., Zaoui, A. (Eds.), Micromechanics of Plasticity and Damage of Multiphase Materials (IUTAM Symposium). Kluwer, pp. 149-156.

Tomita, Y., Iwamoto, T., 1995. Constitutive modelling of trip steel and its application to the improvement of mechanical properties. International Journal of Mechanical Sciences 37, 1295-1305.

Tomita, Y., Iwamoto, T., 2001. Computational prediction of deformation behavior of trip steels under cyclic loading. International Journal of Mechanical Sciences 43, 2017-2034.

Turteltaub, S., Suiker, A.S.J., 2005. Transformation-induced plasticity in ferrous alloys. Journal of the Mechanics and Physics of Solids 53, 1747-1788.

Voyiadjis, G.Z., Abed, F.H., 2006. A coupled temperature and strain rate dependent yield function for dynamic deformations of bcc metals. International Journal of Plasticity 22, 1398-1431.

Willis, J.R., 1982. Mechanics of Solids, the Rodney Hill 60th Anniversary Volume. Oxford Pergamon, Ch. Elasticity Theory of Composites, pp. 653-686.

Wolff, M., Böhma, M., Helm, D., 2008. Material behavior of steel - modeling of complex phenomena and thermodynamic consistency. International Journal of Plasticity 24, 746-774.

Young, C.C., 1988. Transformation toughening in phosphocarbide-strengthened austenitic steels. Ph.D. Thesis, MIT, Cambridge, Massachusetts.

Zukas, J.A., Scheffer, D.R., 2000. Practical aspects of numerical simulations of dynamic events: effects of meshing. International Journal of Impact Engineering $24,925-945$ 